Portland State University

PDXScholar

Dissertations and Theses

Dissertations and Theses

Spring 5-25-2017

\title{
Utilization of Remote Sensing in Drought Monitoring Over Iraq
}

Yousif Almamalachy

Portland State University

Follow this and additional works at: https://pdxscholar.library.pdx.edu/open_access_etds

Part of the Civil and Environmental Engineering Commons, and the Hydrology Commons Let us know how access to this document benefits you.

Recommended Citation

Almamalachy, Yousif, "Utilization of Remote Sensing in Drought Monitoring Over Iraq" (2017).

Dissertations and Theses. Paper 3996.

https://doi.org/10.15760/etd.5880

This Thesis is brought to you for free and open access. It has been accepted for inclusion in Dissertations and Theses by an authorized administrator of PDXScholar. Please contact us if we can make this document more accessible: pdxscholar@pdx.edu. 
Utilization of Remote Sensing in Drought Monitoring Over Iraq

\author{
by \\ Yousif Almamalachy
}

A thesis submitted in partial fulfillment of the requirements for the degree of

Master of Science

in

Civil and Environmental Engineering

Thesis Committee:

Hamid Moradkhani, Chair

Scott Wells

Yangdong Pan

Portland State University

2017 
C)2017 Yousif Almamalachy 


\begin{abstract}
Agricultural drought is a creeping disaster that overshadows the vegetative cover in general and cropland specifically in Iraq, a country that was well known for its agricultural production and fertile soil. In the recent years, the arable lands in Iraq experienced increasing land degradation that led to desertification, economic losses, food insecurity, and deteriorating environment. Remote sensing is employed in this study and four different indices are utilized, each of which is derived from MODIS satellite mission products. Agricultural drought maps are produced from 2003 to 2015 after masking the vegetation cover. Year 2008 was found the most severe drought year during the study period, where drought covered $37 \%$ of the vegetated land. This part of the study demonstrated the capability of remote sensing in fulfilling the need of an early warning system for agricultural drought over such a data-scarce region.

This study also aims to monitor hydrological drought. The Gravity Recovery and Climate Experiment (GRACE) satellite-derived monthly Terrestrial Water Storage (TWS) is the hydrological drought indicator, that is used to calculate the deficit. Severity of drought events are calculated by integrating monthly water deficit over the drought period. In addition, drought recovery time is assessed depending on the estimated deficit. Major drought events are classified into several levels of severity by applying a drought monograph approach. The results demonstrated that GRACE TWS is a reliable indicator for drought assessment over Iraq, and provides useful information for decision makers which can be utilized in developing drought adaptation and mitigation strategies.
\end{abstract}




\section{Dedication}

I dedicate this work to my loving mother, whose prayers in the middle of nights were the bridge I needed to complete this journey. To the

fond memory of my father, who implanted high ethical values in me. To my

brother and sister for their unyielding support. To my kids, the source

of positive energy in my life. To my amazing wife, whose

sacrificial care for me and our children made it

possible for me to complete this

work. 


\section{Acknowledgments}

First and foremost, I am ever grateful to God, the Creator, the Almighty, and the Guardian, whose many blessings have made the completion of this thesis possible. I am very fortunate to have performed my graduate work at a university as collaborative as Portland State University; therefore, there are many people to thank for their part in my success. I would first like to thank my advisor, Dr. Hamid Moradkhani, for giving me a home in his lab and support over the years. I am grateful for his guidance and the opportunities he has afforded me, which are essential elements to strive forward and complete this work. He is incredibly organized and a great problem solver, both of these qualities were immensely helpful in moving my thesis forward. Under his mentorship, I have learned research methodology, which is an invaluable tool to have as my career moves forward. Dr. Moradkhani is also exceptionally kind and caring person and would do anything possible to keep his students and the people around him feel comfortable and supported. I will remember my time in the lab and our meetings very fondly.

I would also like to thank my thesis committee members, Dr. Scott Wells, and Dr. Yangdong Pan, for their contributions to this work. Each has dedicated lots of time and effort to make this work better by giving me many insightful suggestions and demonstrated a sincere interest in my work. I am fortunate to have such a group of intelligent scientists on my committee.

I would like to recognize the members of the Remote Sensing lab who have all contributed to the progress I have made. It's your bright ideas that kept the research engine running. The lab members are a wonderful group of people who I have enjoyed working with and learning from.

I would like to acknowledge the full financial support of the Iraqi government represented by the Higher Committee for Education Development (HCED). They 
provided the chance to complete my graduate education in the US. Their financial support was not only limited to tuition fees, but their generosity extended to cover the living expenses, and health insurance for me and my family.

I would like to thank my guarantors, who have faith in me and risked their financial assets for the purpose of guaranteeing scholarship expenses to my sponsor in case something goes wrong. This sacrifice was essential for the initiation of the scholarship program, and without it; the scholarship would not be granted. Those very few people who took this risk and supported me are my mother-in-law, her two close friends, my mother, and my two aunts. I highly appreciate your trust in me, without you this would not be possible.

Finally, I would like to express the deepest gratitude to my family. Mom, Rand, and Hassan, you have all provided support, encouragement and interest in my thesis. Thanks for listening to my problems and providing perspective. I would like to thank my Father. You have taught me how to deal with life difficulties and implanted in me the will to pursue success and always follow the straight path. Your memory will be with me always, and I will be ever grateful to your sacrifices. I would not be who am I today without you all. I would like to thank my wife, Wurood. You have been continuously supportive of my graduate education. Thank you for the continuous care of me and our children all times, day and night. Thank you for those times when you spent the night till dawn watching over me in case I needed help, it is those times that one might feel lonely, but you dissipated the loneliness with your kind presence. You have been patient with me when I'm frustrated, you celebrate with me when even the littlest things go right, and you are there whenever I need you to just listen. I would like to thank my kids, Fatima and Haider for immersing me with positive energy when I feel down and depressed. You are the cure of my heart. 
Contents

Abstract $\quad$ i

Dedication $\quad$ ii

Acknowledgments $\quad$ iii

List of Tables vii

List of Figures viii

\section{Chapter One: Introduction}

1.1 Drought Background and Its Effect on Iraq . . . . . . . . . . . 1

1.2 Drought Types .......................... 3

1.2.1 Agricultural Drought ............... 3

1.2.2 Hydrological Drought . . . . . . . . . . . . . 6

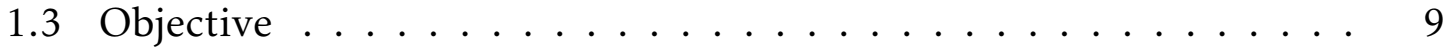

1.4 Study Area . . . . . . . . . . . . . . . . 10

\section{Chapter Two: Agricultural Drought}

2.1 Data and Methods . . . . . . . . . . . . . . . . 14

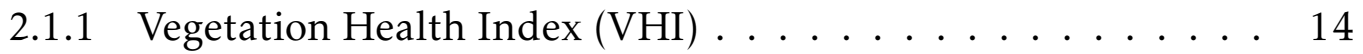

2.1 .2 Vegetation Drought Index $($ VDI $) \ldots \ldots . . . . . . . .17$

2.1.3 Visible and Shortwave infrared Drought Index (VSDI) . . . . 19

2.1.4 Temperature-Vegetation Dryness Index (TVDI) . . . . . . . 22

2.1 .5 Masking Vegetation ................ 24

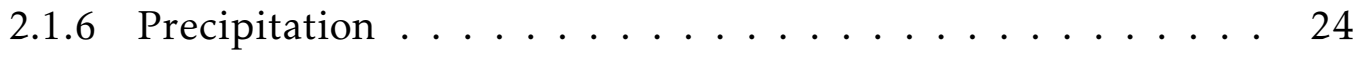

2.2 Results and Discussion . . . . . . . . . . . . 25 


\section{Chapter Three: Hydrological Drought}

3.1 Data and Methods ..................... 36

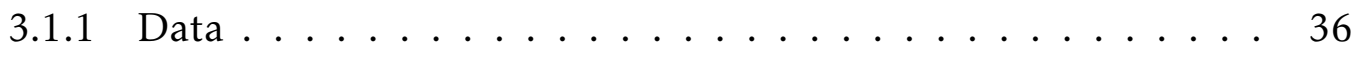

3.1.1.1 Terrestrial Water Storage (TWS) . . . . . . . . 36

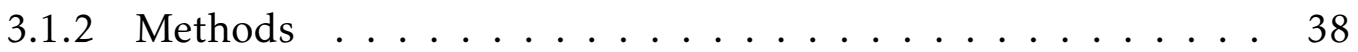

3.1.2.1 Drought Deficit ............. 38

3.1.2.2 Drought Severity ............. 39

3.1.2.3 Drought Recovery ............... 39

3.1.2.4 Classification ................ 41

3.1.2.5 Trend analysis ................ 43

3.2 Results and Discussion .................. . . 43

Chapter Four: Conclusion

$\begin{array}{ll}\text { REFERENCES } & 55\end{array}$ 


\section{List OF TABLES}

Table 1 Classification of agricultural drought based on VHI. . . . . . 17

Table 2 Classification of agricultural drought based on VDI. . . . . . 19

Table 3 Classification of agricultural drought based on VSDI. . . . . 22

Table 4 Classification of agricultural drought based on TVDI. . . . . . 24

Table 5 Classification of hydrological drought based on TSDI $\ldots . .42$

Table 6 Summary of hydrological drought events . . . . . . . . . 46

Table 7 Comparison of drought severity lines with CTSD line. . . . . 50 


\section{List OF Figures}

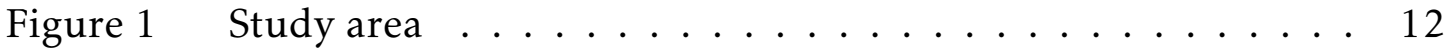

Figure 2 Aridity distribution in the region $\ldots \ldots \ldots \ldots$

Figure 3 VHI calculation method $\ldots \ldots \ldots \ldots \ldots$

Figure 4 VDI calculation method $\ldots \ldots \ldots \ldots \ldots$

Figure 5 Agricultural drought-VHI results $\ldots \ldots \ldots \ldots \ldots$

Figure 6 Agricultural drought-VDI results $\ldots \ldots \ldots \ldots . \ldots 27$

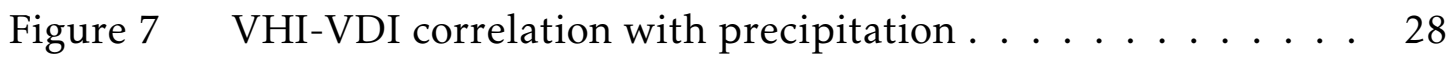

Figure 8 NDVI-NDWI components correlation . . . . . . . . . . . 29

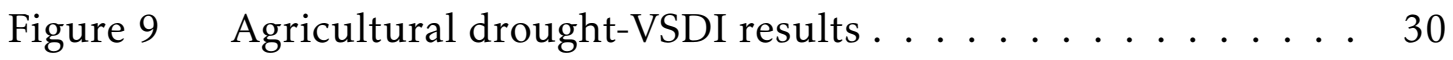

Figure 10 Agricultural drought-TVDI results . . . . . . . . . 33

Figure 11 Agricultural drought-FAO statistics . . . . . . . . . . . . 34

Figure 12 Area weighting of $1 \mathrm{x} 1$ degree grid cells . . . . . . . . . 37

Figure 13 The empirical cumulative distribution function . . . . . . 40

Figure 14 Drought Monograph . . . . . . . . . . . . . 43

Figure 15 Hydrological Drought- Deficit . . . . . . . . . . . . 45

Figure 16 Hydrological Drought-Severity . . . . . . . . . . 47

Figure 17 Hydrological Drought-Recovery . . . . . . . . . . . . 48

Figure 18 Hydrological Drought-Severity Classification . . . . . . . 50

Figure 19 Hydrological Drought-TWSA,T, and P Trends . . . . . . . 51 


\section{Chapter One: Introduction}

\subsection{Drought Background and Its Effect on Iraq}

Drought is identified by the National Oceanic and Atmospheric Administration as "deficiency in precipitation over an extended period, usually a season or more, resulting in a water shortage causing adverse impacts on vegetation, animals, and/or people" (NOAA, 2008, p. 1). Van Loon (2015) described the sequence of drought development, where a drought event starts with a prolonged shortage in precipitation rate named as meteorological drought, which develops into a reduced water availability in root-zone soil moisture resulting in decreased vegetation cover known as agricultural drought. Van Loon's research pointed that hydrological drought emerges after the development of meteorological and agricultural droughts, and it can be defined as the long-term below-normal amount of water available in the terrestrial part of the hydrological system including surface water (e.g. lakes, rivers, and reservoirs), soil moisture, and ground water. Finally, Socioeconomic drought emerges as the combined impact of the three aforementioned droughts, where water demand obscures water supply and the deficiency is projected on environmental, economic, and societal sectors (NOAA, 2012). Although drought has no universal definition in the meantime (Lloyd-Hughes, 2014), it can be simply described as the deficit in precipitation, and terrestrial water storage (the sum of surface and subsurface water), which adversely affects agriculture, environment and economy. Drought can have a wide range of temporal extent, it can last from few months to multiple years (Madadgar \& Moradkhani, 2013a, 2013b, 2014; Mishra \& Singh, 2010). Further drought description and characteristics are discussed in several studies, Mishra and Singh (2010), Sheffield and Wood (2011), and Van Loon (2015).

Although, the primary cause of drought is attributed to meteorological anoma- 
lies represented by shortage of precipitation below normal levels, anthropogenic activities can also be a factor in the occurrence of drought (Van Loon et al., 2016). Humans contribution in drought manifestation can either be direct such as ground water abstraction or indirect such as the greenhouse gas (GHG)-induced global warming (Gustard et al., 1997; Zhao \& Dai, 2015). Many studies have focused on monitoring the effects of anthropogenic activities on drought exacerbation. For example, Ahmadalipour et al. (2017a) investigated the effects of global warming and climate change on drought characteristics over the US, and their findings showed an anticipated increment during the summer in the spatial extent and intensity of meteorological drought. Similarly, a significant part of Europe is expected to experience more intense and longer hydrological drought events due to global warming (Roudier et al., 2016). In addition to the aforementioned studies, further research about climate change, and its effect on climatic variables and extreme events can also be found in Cheng et al. (2016), Madadgar and Moradkhani (2013b), Rana and Moradkhani (2016), Rana et al. (2016), and Schlaepfer et al. (2017).

UNESCO (2014) highlighted that Iraq has suffered from several drought events in the period of 2003-2012, where different factors contributed in the occurrence of such events including low rainfall rates, higher temperatures, lower water income from upstream countries, and low efficiency in water utilization. These factors caused a multidimensional effect on the region such as, lower discharge of Tigris and Euphrates, less available and more saline ground water, population migration, and agricultural degradation (UNESCO, 2014). Despite all the aforementioned effects of drought over Iraq, and the fact that drought is known to be the costliest extreme natural phenomenon (Dai \& Zhao, 2016; Van Loon, 2015; Yan et al., 2017), only few studies have addressed this phenomenon in a comprehensive and updated manner in this region. 


\subsection{Drought Types}

\subsubsection{Agricultural Drought}

Agriculture in Iraq is known to be the second contributor to revenues after oil; and it is still responsible for recruiting about $20 \%$ of the work force even after the decline of its share in the GDP from 9\% in 2002 to 3.3\% in 2008 (FAO \& World Bank, 2011). Agricultural drought can be defined as the inadequacy of soil moisture needed to fulfill vegetation needs resulting from prolonged shortage of precipitation, known as the meteorological drought and usually leads to crop failure (Van Loon, 2015). A previous study assessed meteorological drought in Iraq between 1980 and 2010, and concluded that drought has shifted from normal to extreme conditions in the last decade, while 2008 was the driest year (AL-Timimi \& AL-Jiboori, 2013). The fact that Iraq experienced serious meteorological drought events combined with decreasing annual flow from Tigris and Euphrates leads by nature to diminished vegetation cover for the period of 2003-2012 (UNESCO, 2014). Agricultural drought can have huge economic impacts, for example, Iran evaluated its loss due to agricultural drought to about 1605 million USD in the crop year 1999-2000 (Salami et al., 2009). Spain loss was estimated of about 2500 million euros in 2005 drought event (European Commission, 2006). California state loss in 2016 was found to be 603 million USD plus 4700 job losses (Medellín-Azuara et al., 2016). And finally, Canadian prairies suffered from agricultural drought during growing seasons in 2001 and 2002 resulting in 3.6 billion USD with 41000 job losses (Wheaton et al., 2005). UNESCO (2014) report highlighted that $40 \%$ of cropland in Iraq was lost in 2008-2009 drought years with unknown economic loss.

Such damages can be mitigated if an effective drought management approach is in place (Yan et al., 2017). This starts with a drought monitoring system that utilizes remote sensing data and provide an early warning tool, which helps build response 
actions (e.g. contingency plans) to mitigate expected drought events (Gunda et al., 2016; Rembold et al., 2015). Rembold et al. (2015) described agricultural drought monitoring approaches and divided them into two groups. The first group is dependent on collected data from weather stations that measures precipitation and other physical parameters to develop drought indicators, which estimates soil moisture deficit. These indicators include the Crop Moisture Index (CMI), Palmer Drought Severity Index (PDSI), and the Surface Water Supply Index (SWSI). Rembold et al. (2015) also described another type of indices that apply a statistical approach to distinguish below normal precipitation rate as an indicator of water deficit such as the well-known Standardized Precipitation Index (SPI). However, weather stations are not always available for every drought-prone region. In fact, even if they are available, they might be sparsely distributed and subject to missing data, which introduce challenges in applying the above approach (Rhee et al., 2010; Ahmadalipour et al., 2017b). However, remote sensing provide an opportunity to overcome these challenges by making the meteorological and biophysical variables available for large-scale area monitoring.

The mentioned capabilities of remote sensing led to the development of the second group of agricultural drought monitoring systems, which utilizes a group of indices referred to as optical remote sensing indices (Rembold et al., 2015; Ahmadalipour et al., 2017b). These indices introduce a more direct approach to monitor drought by monitoring vegetation health status directly through the integration of different bands of the capturing satellite sensor. Numerous studies have utilized optical drought monitoring system successfully and various number of indices were developed, each of which has its own advantages and limitations. For example, Gebrehiwot et al. (2016) utilized the Normalized Difference Vegetation Index (NDVI) to monitor agricultural drought over Ethiopia from 1998 to 2013. 
The study monitored crop fields during growing season using Vegetation Condition Index (VCI), which is solely dependent on NDVI, and reached to the conclusion that VCI-based analysis can accurately distinguish the beginning of agricultural drought events in addition to their variation spatially and temporally. In Indonesia, Vegetation Health Index (VHI) proved its effectiveness as an early warning system for agricultural drought (Sholihah et al., 2016). The study combined the remotely sensed Land Surface Temperature (LST) and NDVI to produce VHI, which in turn was able to track the spatio-temporal dynamics of the drought events in 2000, 2005, 2010, and 2015 in addition to tracking each drought event severity level. Rhee et al. (2010) proposed the Scaled Drought Condition Index (SDCI), a drought index that was created by combining other remotely sensed datasets like LST, precipitation, and NDVI, after scaling and weighting each of them. SDCI was tested over humid and arid regions in the US between 2000 and 2009, and outperformed VHI in both environments. It was also, more correlated with in-situ indices like PDSI, Z-Index, 3-month SPI, 6-month SPI, and USDM maps.

Despite the great importance of agriculture in Iraq, agricultural drought has not been targeted directly over this region. Most of the studies have focused on meteorological drought as a proxy to monitor agricultural drought. For example, UNESCO (2014) employed SPI for drought monitoring and extensively analyzed the affected sectors by meteorological drought. They approached the agricultural consequences only by mentioning the degradation in the amount of harvested crops and the decrement of vegetation cover between 2009 and 2012. Other studies over Iraq focused on either small area (e.g., one governorate or a portion of it) or short period of study. For example, Eklund and Seaquist (2015) studied meteorological, agricultural, and socioeconomic drought over Duhok governorate in northern Iraq using Enhanced Vegetation Index (EVI) to monitor agricultural drought between 
2000 and 2011. They concluded that the study area experienced agricultural drought between 2007 and 2009, emphasizing on 2008 as the peak of the drought event. Hassan et al. (2012) used NDVI to monitor areal variation in vegetation cover over Babylon governorate in 1976, 1986, 1992, 2003, and 2010. The results of that study showed that a decrement in vegetation cover referred to as desertification is increasing with time. Agricultural drought was monitored over three adjacent governorates (Mosul, Kirkuk, and Salah al-Din) for the period of 2000 to 2010 using NDVI as a monitoring index (Muhaimeed \& M, 2013). The study found that the drought conditions in 2007-2008 growing season was the most severe with the lowest value of NDVI.

Agricultural drought contributed to food insecurity and poverty increase in Iraq by reducing local agricultural production and increasing the amount of food importing in order to meet the population needs (UNESCO, 2014). A United Nations report in accordance with the Iraqi Ministry of Planning stated the Iraq's population growth from 22 million in 1997 to 34 million in 2012 (UN, 2014). This population growth is expected to exacerbate the effects of drought on food security.

\subsubsection{Hydrological Drought}

While meteorological and agricultural drought over Iraq were approached directly or indirectly, hydrological drought did not receive much attention in this region. However, an attempt to quantify Terrestrial Water Storage (TWS) loss followed by groundwater (GW) depletion estimation has been made by Mulder et al. (2015) and Voss et al. (2013), and showed a declination in both TWS and GW during their study periods.

Globally, Numerous studies have addressed this type of drought by different methods. In the western United states, Madadgar and Moradkhani (2013b) studied hydrological drought by means of statistical analysis of stream flow data in 
the Upper Klamath river basin by combining the streamflow drought index (SDI) (Nalbantis, 2008) with Copula functions to evaluate the behavior of historic hydrological drought events and project the future droughts. The key findings of the study showed that 45 drought events have occurred between 1920 and 2009 with a maximum duration of 8 months, while intense extreme events are not expected to occur in the future. Hydrological drought in Europe was investigated by proposing the Regional Drought Area Index (RDAI), a drought index that utilizes streamflow to provide areal estimation of hydrological drought (Fleig et al., 2011). The study concluded that RDAI can be an effective index for hydrological drought monitoring on a daily scale. Also, the study pointed that RDAI has the potential to be used across different time scales. Hosseinzadeh Talaee et al. (2014) investigated hydrological drought over western Iran from 1969-1970 hydrologic year to 2008-2009 by employing Standardized StreamFlow Index (SSFI). Atmospheric circulation patterns (ENSO, NAO) and their effect on hydrological drought was also investigated in this study. The results showed that the warm phase of ENSO was the cause of below-normal river discharges, which in turn caused sever to extreme drought events especially in 2007-2008 and 2008-2009 hydrologic years, while NAO showed week correlation with SSFI even with lag correlation analysis. DeChant and Moradkhani (2014) were able to enhance the reliability of hydrological drought forecasting over the Upper Colorado river basin in the US by employing data assimilation and sequential Bayesian combination approaches. DeChant and Moradkhani (2015) furthered that study by developing an approach to estimate drought recovery time and rate conditioned on initial condition characterized by data assimilation. The drought monitoring and forecasting was enhanced by employing a more sophisticated and accurate data assimilation approach combined with a multivariate statistical approach using Copula functions and the approach 
was implemented over the Pacific Northwest US (Yan et al., 2017).

Despite all the scientific advancements in remote sensing and the massive data provided by different satellites, utilization of remote sensing data in hydrological drought monitoring is still finite (Van Loon, 2015), with the focus on meteorological and agricultural drought monitoring depending on ground based station measurements (Ahmadalipour et al., 2017b). In fact, remote sensing data overcomes some of the limitations attached to point based station data such as the limited spatial coverage, and the inability to trace the spatial variation of drought (Ahmadalipour et al., 2017b). Thomas et al. (2014) proposed an approach to monitor hydrological drought utilizing the Gravity Recovery and Climate Experiment (GRACE) mission. The approach was applied over four different regions, and was proved to be useful especially in data limited areas. Zhang et al. (2016) followed Thomas et al. (2014) by applying the same approach over the Yangtze river basin in China and for longer periods. The aforementioned approach provides quantitative sense of hydrological drought monitoring. In order to provide useful information for decision makers, a classification of hydrological drought is needed. Yirdaw et al. (2008) proposed an approach that has been increasingly used in scientific literature to classify prolonged drought events.

GRACE has a unique concept behind it. Unlike any other satellites, it does not capture the spectral reflectance of the earth. Instead, it measures the changes in earth's gravity in a specific location and translate these changes (anomalies) into Terrestrial Water Storage Anomaly (TWSA). GRACE is comprised of two identical satellites where one orbits behind the other in a distance of $220 \mathrm{Km}$ approximately. This distance between the twin satellites is the key of GRACE ability in measuring gravity change. It is a known fact that a large mass owns a large gravity force, therefore, if the first satellite orbits over a large mass on earth (e.g. a mountain), it 
will be pulled away from the second satellite and the distance between them will increase until the second satellite reaches the same mass. This distance difference is recorded using an extremely precise microwave ranging system known as K-band Ranging System (KBR). This distance difference is a reflection of earth's gravity change, which is analyzed and processed to reflect the TWSA. Further technical details about GRACE can be found in (NASA/GSFC, 2002).

Because of GRACE's unique ability in measuring the change of water amount available in the terrestrial part (including ground water), it has a wide range of applications in the scientific literature in addition to hydrological drought monitoring such as, basin total discharge estimation (Syed et al., 2005), groundwater storage monitoring (Famiglietti et al., 2011; Ouyang et al., 2016; Rodell \& Famiglietti, 2002), vegetation growth and greenness monitoring (A et al., 2015; Yang et al., 2014), and evapotranspiration estimation (Rodell, 2004).

\subsection{Objective}

The purpose of this study is to employ remote sensing capabilities to conduct a nationwide agricultural and hydrological drought monitoring for the period between August 2002 and December 2015 over a data-inaccessible region such as Iraq. On the agricultural drought side, the Moderate Resolution Imaging Spectroradiometer (MODIS) onboard TERRA satellite products will be utilized in this study for agricultural drought monitoring over Iraq given the success it has shown in previous studies (Son et al., 2012; Yan et al., 2016). The drought will be monitored through multiple indices. Drought areal coverage will be calculated for each index and each severity class. For hydrological drought monitoring, GRACE will be used following the approach by Thomas et al. (2014) with slight modification in order to provide a more physically linked drought monitoring. The monitoring will be through studying drought characteristics by quantifying drought deficit, severity, 
and recovery in addition to classifying major drought events to provide useful information for decision makers in hydrological drought monitoring.

\subsection{Study Area}

The Republic of Iraq is located in southwestern Asia, forming the eastern boundary of the Arab homeland. Surrounded by Turkey from the north, Iran from the east, Syria and Jordan from the west, Saudi Arabia and Kuwait from the south as shown in Figure 1a. According to the Food and Agriculture Organization (FAO) of the United Nations (Omer, 2011), topography of the country can be divided into four regions: Mountainous region (21\%), Sedimentary plain (30\%), Desert plateau (39\%), Undulating terrain (10\%). Iraq's climate mainly ranges between arid and semi-arid condition with the exception of the northeastern part. This is verified in Figure 2 by using De Martonne 's aridity index, an aridity index that incorporates temperature and precipitation data as climatic variables (De Martonne, 1926). Precipitation and temperature data are obtained from the Global Land Data Assimilation System (GLDAS): Noah land surface model version 1 monthly data with 0.25 X 0.25 degree spatial resolution (Rodell et al., 2007). The gridded data are masked for Iraq, and modified to reflect the rainfall in $(\mathrm{mm} / \mathrm{month})$ and surface temperature in ${ }^{\circ} \mathrm{C}$. The spatial pattern of rainfall distribution can be summarized into the western desert receiving less than $100 \mathrm{~mm}$ per year, the Mesopotamian flood plain and Jezira area stretching from northwest to the southeast receiving 100$300 \mathrm{~mm}$ per year, the foothills in the mid-northern part receiving about 300-700 $\mathrm{mm}$ per year, and the mountainous region in the far north receives more than 700 mm per year (Jassim \& Goff, 2006). Apparently, rainfall spatial patterns are closely related to the topography of the country where each of the four aforementioned patterns has unique elevation range, the elevation distribution can be clearly seen in Figure 1b. About $90 \%$ of the precipitation is received between November and 
April, which makes this period in addition to October and May; a growing season of agriculture in Iraq (UN, 2014; World Bank, 2006). In addition to this variability in precipitation, temperature also varies seasonally from more than $48^{\circ} \mathrm{C}$ in July to less $0{ }^{\circ} \mathrm{C}$ in January (World Bank, 2006). Climatic factors such as, high temperature, low rainfall, and high wind speed escalate evaporation rate in the region to high levels. For instance, Abu Dibbis lake in the central part of the country has an evaporation rate of about $2170 \mathrm{~mm}$ per year (Omer, 2011).Tigris and Euphrates are the two main rivers in the study area, and they stretch along the region from northwest to southeast as shown in Figure 1a.

Iraq is mainly dependent on oil revenues; however, agriculture is the second contributor to the annual revenue after oil (FAO \& World Bank, 2011). The cultivable area in Iraq represents about $27 \%$ of the total area, only $67 \%$ of the cultivable area has been utilized for actual agricultural production (Abd-El-Mooty et al., 2016; Omer, 2011). Iraq's main agricultural production is focused on wheat and barley forming about $80 \%$ of the production (FAO \& World Bank, 2011). Two farming methods can be distinguished in Iraq: rainfed which is mainly concentrated in the northern part of the country, and irrigated as in the central and southern parts of the country (UNESCO, 2014). 
(a)

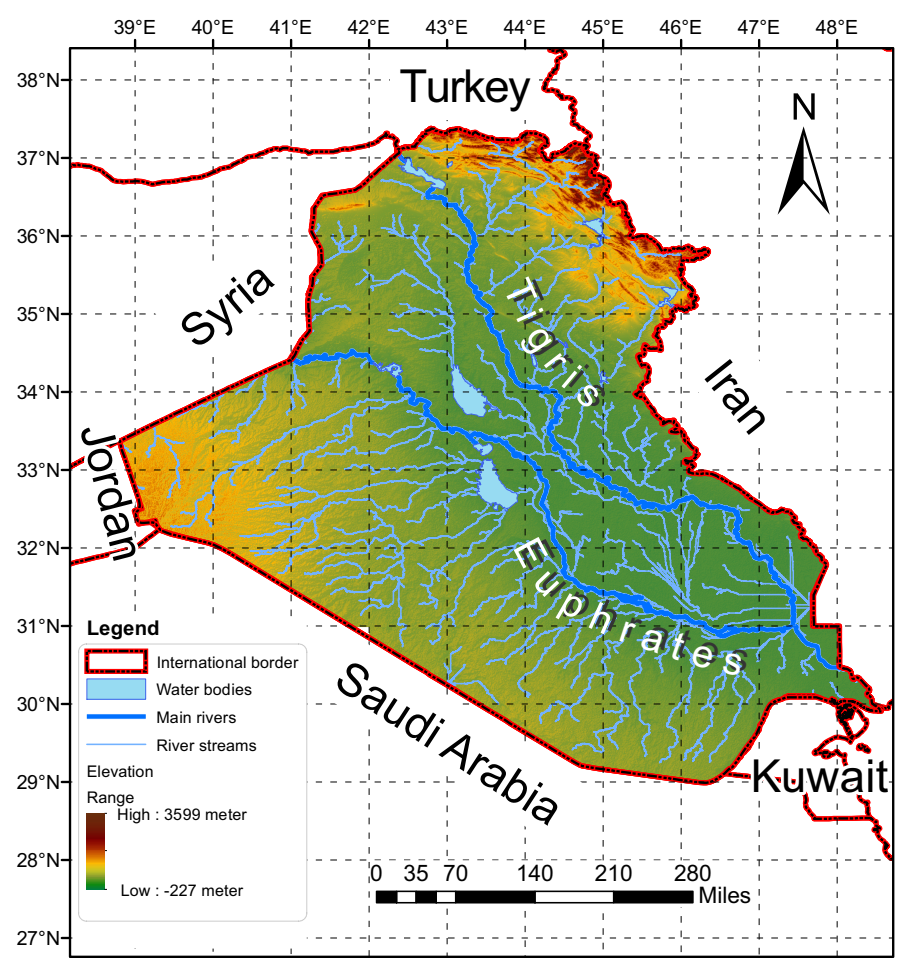

(b)

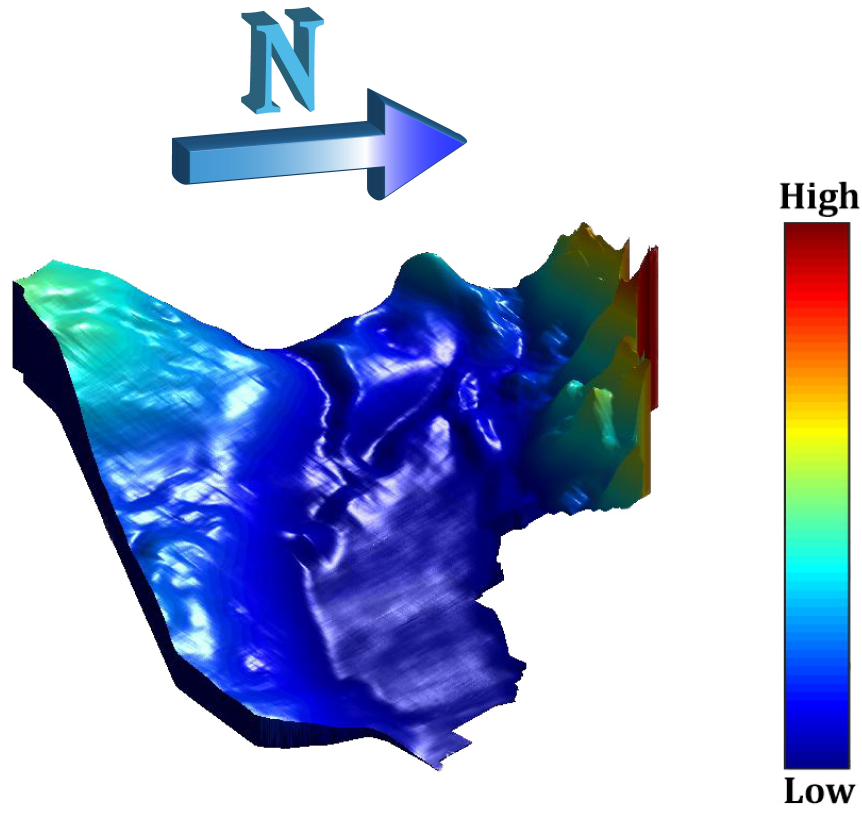

Elevation

Figure 1: (a) The Republic of Iraq administrative boundary, water bodies, rivers, and elevation. (b) A 3D model of Iraq's elevation. DEM was obtained from ASTER GDEM V2 (NASA JPL., 2009) from USGS Earth Explorer website (https: / / earthexplorer.usgs.gov). 


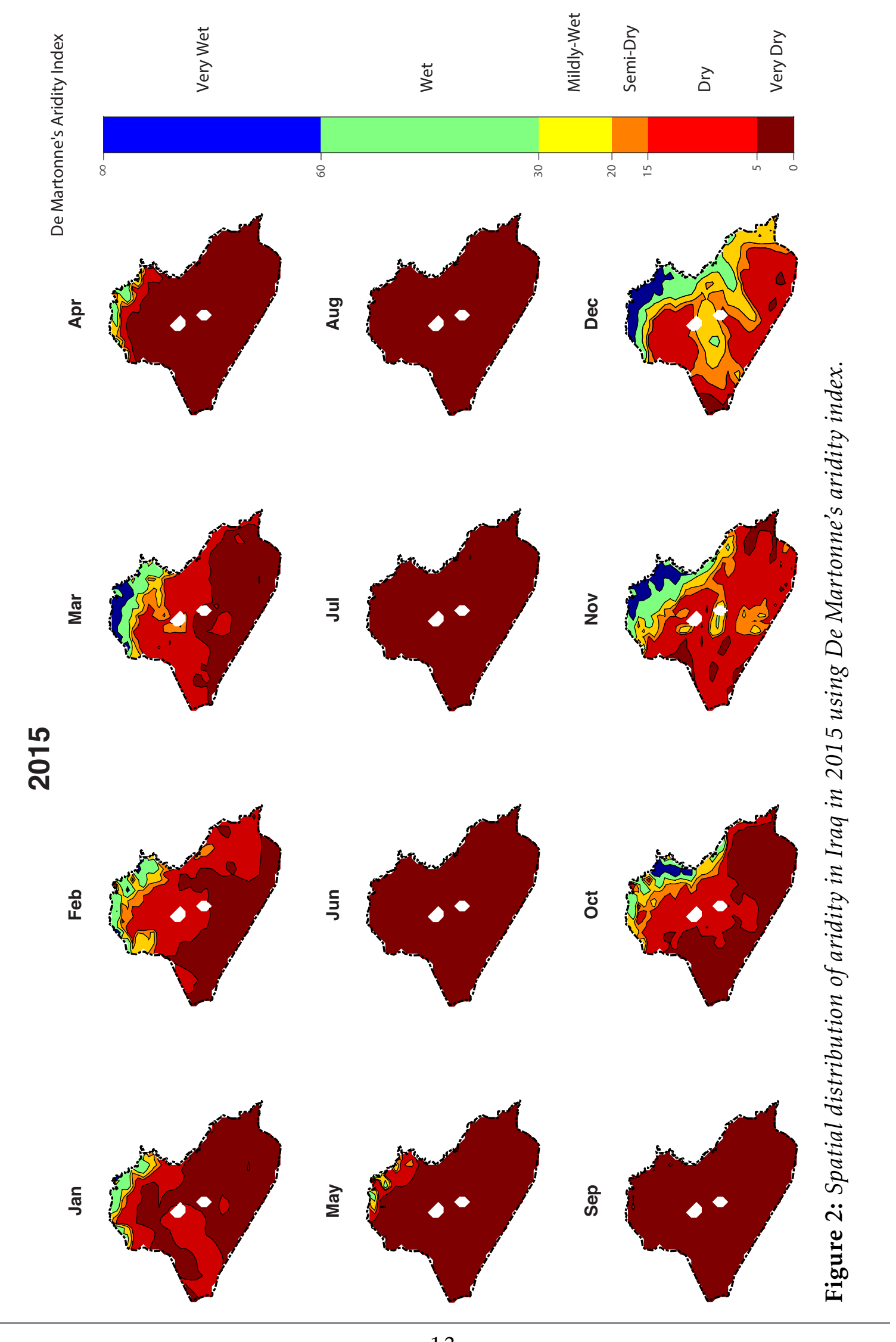




\section{Chapter Two: Agricultural Drought}

\subsection{Data and Methods}

\subsubsection{Vegetation Health Index (VHI)}

NDVI is known to be one of the earliest remote sensing indices that has been used to monitor drought starting in the 1980s (Anyamba \& Tucker, 2012). However, NDVI has certain limitations such as saturation of vegetation canopy, cloud cover, and soil background effect. Rahimzadeh-Bajgiran et al. (2012) highlighted other NDVI limitations for drought monitoring purposes including the noticeable lag time between rainfall and NDVI response in addition to the poor response of NDVI to significant rainfall events in the growing season. In order to enhance drought monitoring, it is advisable to combine NDVI with other parameters (Sruthi \& Aslam, 2015). Kogan (1995) proposed VHI, a vegetation index that relies on NDVI and temperature as its main components. It is important to mention that VHI is based on the assumption that the relation between vegetation and temperature is negative, that is, vegetation experience stress when temperatures goes high. One of the merits of VHI, is the ability to detect the false drought signal that may arise from excessive moisture condition (Kogan, 1995; Singh et al., 2003). This phenomenon happens when an area is subjected to high rainfall rate, then the soil moisture will be high enough to damage the vegetation cover (e.g., crops) and give a signal of a drought event. This misleading detection of drought is likely to happen if only a vegetation index is used to monitor the area such as NDVI, but with the combination of temperature; this issue can be avoided since rainy weather usually occurs in temperatures favorable for vegetation.

VHI has been widely used over different regions of the world with different environmental conditions (Rojas et al., 2011), and is considered a potent indicator for monitoring agricultural drought from a vegetation stress perspective 
(Ahmadalipour et al., 2017b). Also, it has been used in a wide range of applications other than agricultural drought monitoring (Karnieli et al., 2010). Although it has been over 20 years since VHI emergence, it is still being used for agricultural drought monitoring. For example, Yan et al. (2016) utilized VHI to monitor agricultural drought over Hai basin in northern part of China, and found that VHI was capable of detecting meteorological droughts over dryland cropped areas. The research also found that VHI has outperformed SPI in terms of accuracy in detecting agricultural droughts over irrigated areas. VHI was also used to monitor agricultural drought over Lebanon from 1982 to 2014, and the results showed VHI's ability to detect three different types of drought regions in the study area (Ghaleb et al., 2015). In 2016, a study over Indonesia has employed VHI to monitor drought over major rice production centers in the country in four different years (2000, $2005,2010,2015)$. The study has affirmed the usefulness of VHI as an agricultural drought monitoring index, and highlighted its ability to detect the spatio-temporal distribution of drought in addition to classifying drought severity (Sholihah et al., 2016). A very recent study by Ahmadalipour et al. (2017b) successfully analyzed the long-term trends of agricultural drought over the US for different vegetation types utilizing VHI from 1982 until 2015.

In order to calculate the vegetation health index, NDVI and temperature must be developed into Vegetation Condition Index (VCI) and Temperature Condition Index (TCI) respectively. The objective of VCI is to separate the fluctuations of NDVI resulting from short-term weather related conditions and the fluctuations resulting from long-term ecosystem effects (Kogan, 1995). While TCI's goal is to monitor vegetation stress from a temperature perspective rather than greenness in order to prevent the mentioned false drought signal (Owrangi, 2011). Also, temperature component in TCI is less sensitive to water vapor than visible light 
bands which in turn lessens the effect of cloud cover on TCI and then VHI as a result (Rojas et al., 2011).

Since NDVI and temperature are the main components of VHI, NDVI data are obtained from MODIS product MOD13C2 (Didan, 2015). The temperature data are obtained from MODIS product MOD11C3 (Wan, 2015). Both of these datasets with a spatial resolution of 0.05 degree were collected on a monthly basis from August 2002 to December 2015 (161 months). MOD11C3 provides temperature as Land Surface Temperature (LST) for day time and night time separately. The formulation of VHI following Kogan (1995) is shown in Figure 3:

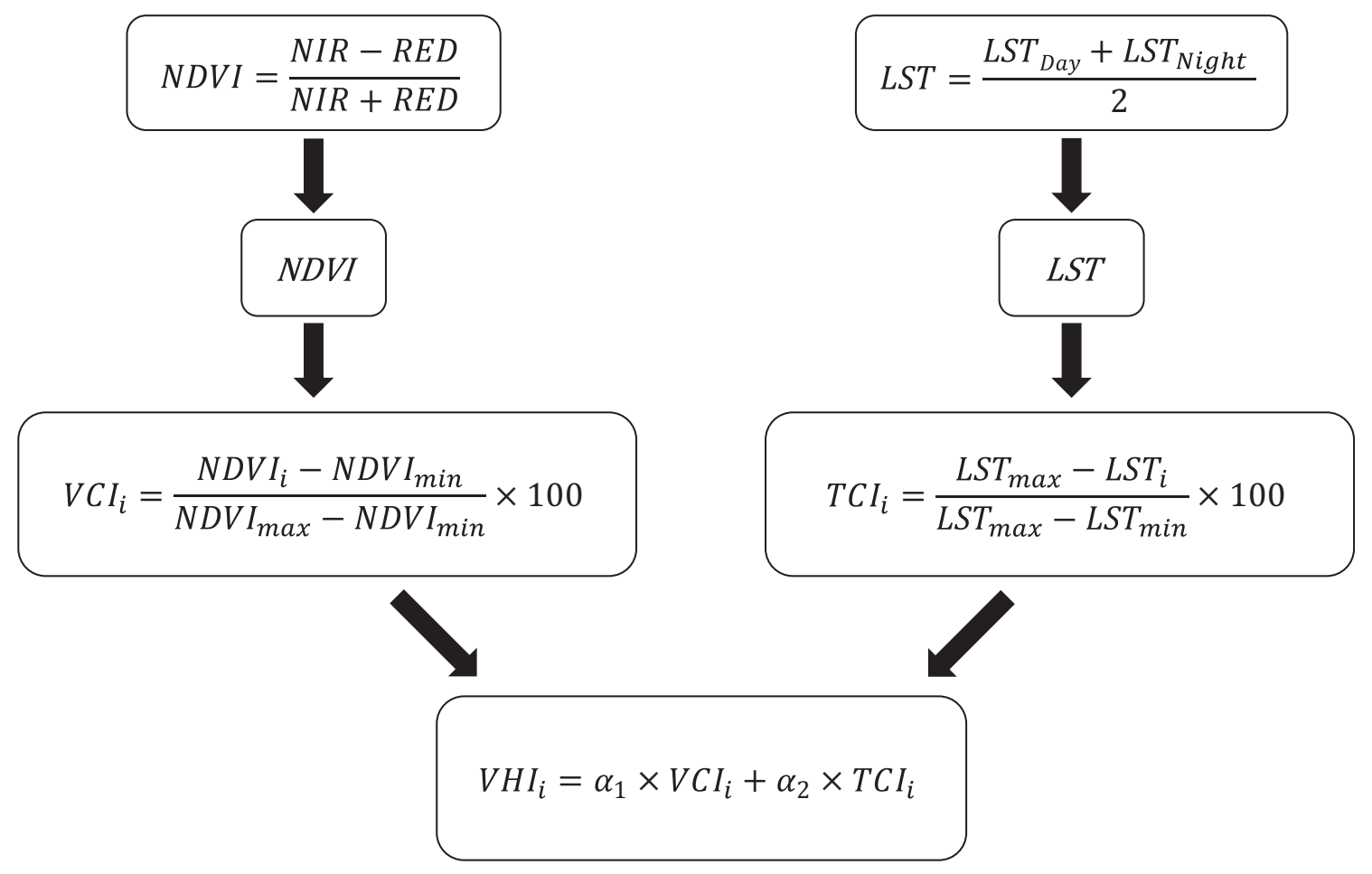

Figure 3: VHI calculation method

For each grid cell, $N D V I_{i}$ represents the value of the $i^{\text {th }}$ month, where $i$ ranges from 1 to 161 months. $N D V I_{\max }$ and $N D V I_{\min }$ are the maximum and minimum NDVI values at each grid cell over all months. $V C I_{i}$ is then calculated for each grid cell and each month. TCI computation is similar to VCI, and VHI is the combi- 
nation of both where $\alpha_{1}$ and $\alpha_{2}$ are equal to 0.5 because moisture and temperature contribution during a vegetation cycle is unknown, therefore, we assume that the shares of VCI and TCI in VHI are equal (Kogan, 2001). Following Tran et al. (2017), VHI is classified into 5 different classes where each represents a level of drought severity as shown in Table 1.

Table 1: Classification of agricultural drought based on VHI.

\begin{tabular}{ll}
\hline Drought severity class & VHI \\
\hline Extreme drought & $\leq 10$ \\
Severe drought & $\leq 20$ \\
Moderate drought & $\leq 30$ \\
Mild drought & $\leq 40$ \\
No drought & $>40$ \\
\hline
\end{tabular}

\subsubsection{Vegetation Drought Index (VDI)}

VDI was recently proposed by Sun et al. (2013) as an agricultural drought monitoring index, and it was successfully applied over China. In that study, VDI and VHI were compared on different levels such as their fulfillment to the assumptions they were built on, their performance with respect to 3-months SPI and 6-months SPI from 753 weather stations, and their performance with respect to in-situ crop yield data.

VDI came out as an upgrade to VHI because the assumption of VHI that NDVI and LST are negatively correlated is not always true (Sun et al., 2013). This implies that there is an inherent uncertainty in VHI's results where positive NDVITemperature relation exists. Although VDI has similar assumption to VHI where its components are assumed to be negatively correlated, Sun et al. (2013) showed that VDI components have a more stable negative correlation than VHI, which makes VDI less uncertain in drought monitoring.

According to Sun et al. (2013), VDI is dependent on Normalized Difference 
Water Index (NDWI) that was first proposed by Gao (1996), and Temperature. As shown in Figure 4, in calculating of VDI, instead of average temperature, the difference between day and night temperatures is used because temperatures difference has high correlation with soil moisture (Sun et al., 2013). Also, Gu et al. (2007) showed that the response of NDWI to drought conditions is more sensitive (rapid) than NDVI.

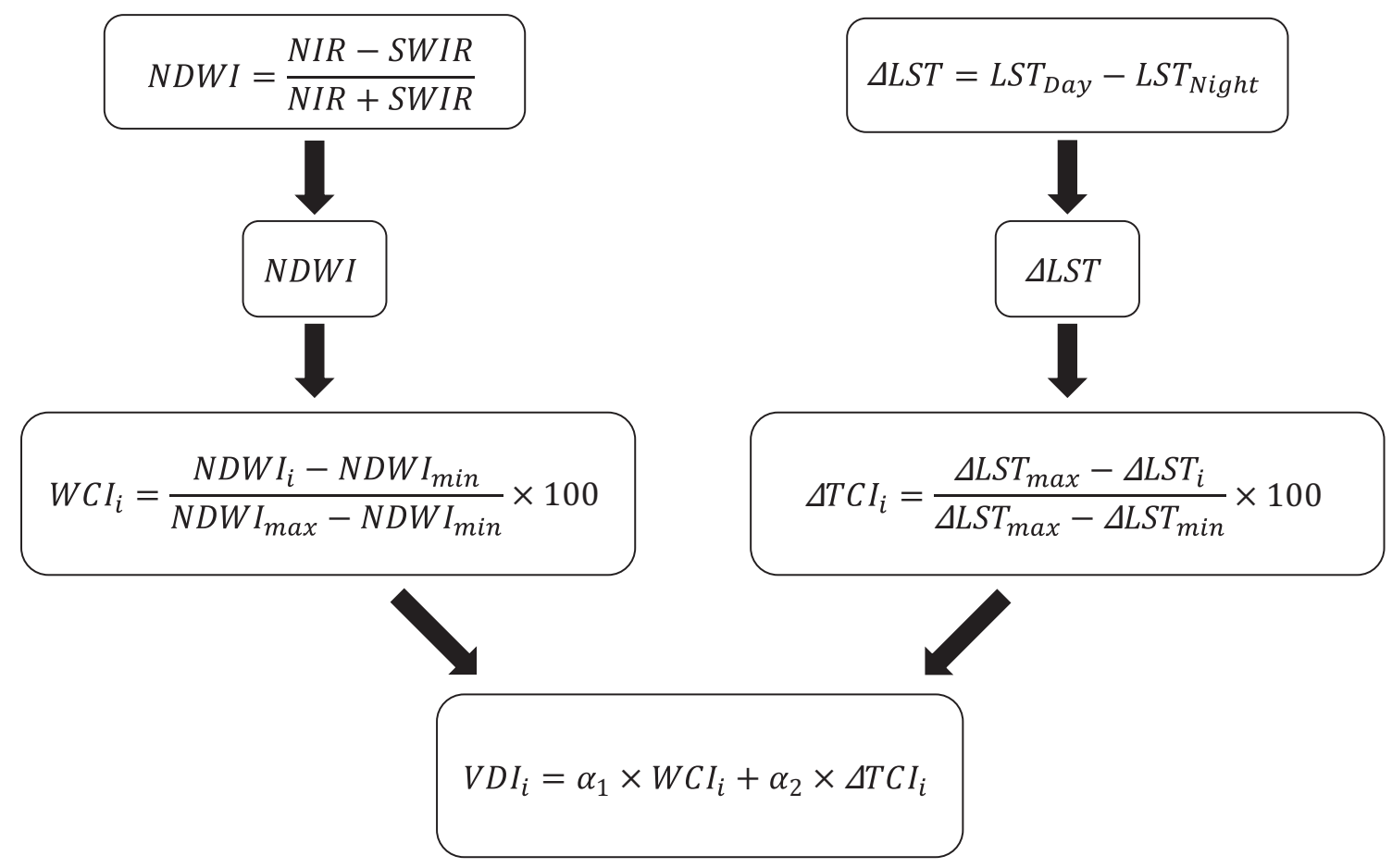

Figure 4: VDI calculation method

Similar to VHI, NDWI is developed into Water Condition Index (WCI) and temperature difference is developed into day-night Temperature Difference Condition Index $(\Delta \mathrm{TCI})$. Both $\mathrm{WCI}$ and $\Delta \mathrm{TCI}$ correlates positively with drought, where higher values reflect good conditions and lower values indicate severe conditions. In general, WCI represents the water deficit in vegetation while $\Delta$ TCI represents the water deficit in soil (Sun et al., 2013).

VDI calculation is pixel by pixel based, where $N D W I_{i}$ represents the value of a 
specific pixel in the $i^{\text {th }}$ month, and $i$ ranges from 1 to 161 months. NDWI $I_{\min }$ and $N D W I_{\max }$ are the minimum and maximum values of NDWI for the same pixel over all months. $\triangle \mathrm{TCI}$ is calculated on the same basis.

In addition to temperature data used for VHI analysis, NDWI requires Near Infrared (NIR) band centered at $857 \mathrm{~nm}$ and Short Wave Infrared (SWIR) band centered at $1230 \mathrm{~nm}$. These information are acquired on a monthly basis from MODIS product MOD13C2 (Didan, 2015). $\alpha_{1}$ and $\alpha_{2}$ are set to 0.5 because WCI and $\triangle \mathrm{TCI}$ are considered to equally contribute in measuring drought severity. Sun et al. (2013) classified drought severity into five classes based on VDI values as shown in Table 2.

Table 2: Classification of agricultural drought based on VDI.

\begin{tabular}{lc}
\hline Drought severity class & VDI \\
\hline Extreme drought & $\leq 13$ \\
Severe drought & $\leq 22$ \\
Moderate drought & $\leq 32$ \\
Mild drought & $\leq 41$ \\
No drought & $>41$ \\
\hline
\end{tabular}

2.1.3 Visible and Shortwave infrared Drought Index (VSDI)

VSDI was proposed as an agricultural drought monitoring index where its validity was tested over Oklahoma, USA by comparing VSDI performance with other remote sensing indices including Land Surface Water Index (LSWI), Surface Water Capacity Index (SWCI), and Normalized Multi-band Drought Index (NMDI) (Zhang et al., 2013a). All these indices including VSDI were compared with a reference index that relies on in-situ soil moisture noted as Fractional Water Index (FWI). VSDI was also compared with the results from the United States Drought Monitor (USDM). The results of that study showed that VSDI outperformed LSWI, SWCI, and LSWI given the highest correlation with the in-situ reference index (FWI). The results also 
showed that VSDI was capable of monitoring moisture in both soil and vegetation, and unlike other indices, it is applicable over different land cover types (Zhang et al., 2013a). Besides, a good agreement was found between VSDI and USDM. However, VSDI like any other index has limitations. The limitation of VSDI is represented by the fact that it is mainly dependent on spectral bands without incorporating temperature, which might affect the index performance in drought areas constrained by temperature rather than precipitation (Zhang et al., 2013a).

Later in 2013, VSDI was further validated by applying it over China and it was shown that it outperformed six other optical drought indices (Zhang et al., 2013b). Also, the study shed light on an important merit of VSDI as a robust index insensitive to cloud cover effect.

VSDI employs the SWIR, Red, and Blue bands in order to monitor drought. It was found that SWIR was the most sensitive band to water content variation in vegetation, followed by the Red band, while Blue band was found to be the least sensitive to vegetation moisture content (Zhang et al., 2013a). Equation 1 expresses VSDI calculation where the difference between sensitive and insensitive bands to vegetation moisture is utilized. Blue band is considered as the reference band and the deviation of SWIR and Red bands from the Blue band represents the variation in vegetation moisture content.

$$
V S D I=1-((S W I R-B l u e)+(\text { Red }- \text { Blue }))
$$

This equation is applied on each pixel at each time step. The bands data were obtained from MODIS product MOD09A1 (Vermote, 2015). It is important to note that SWIR here is band 6 not 7 similar to the one used previously in VDI calculation. Unlike previously used MODIS products, MOD09A1 has an 8-day 
temporal resolution and $500 \mathrm{~m}$ spatial resolution, which made the calculation of VSDI for the whole period of study challenging given the massive data and long processing time required to achieve this goal. In order to overcome this problem, we chose a month that is more sensitive than other months to vegetation variation. Growing season in Iraq starts from October-September until April- May of each year (World Bank, 2006). Since April is at the end of the growing season, we chose this month to be the representative month of the year for vegetation monitoring purposes, because vegetation is expected to be at its peak and any slight positive or negative impact on vegetation would be first noticed in this month. This also has been verified by plotting different months using VHI and VDI (not shown). Finally, April features a clear sky conditions, which reduces uncertainty in remote sensing monitoring for agricultural drought monitoring over the region. Therefore, VSDI data is downloaded for the 8-day composite of April 15-23 of each year for the period of the study. MOD09A1 is also different from MOD13C2 and MOD11C3 in terms of scene size. The latter covers Iraq with one scene, while MOD09A1 covers Iraq by 4 scenes. Numerically, MOD09A1 covers Iraq by 2,075,486 gird cells which is about 120 times the amount of pixels that covers Iraq in MOD13C2 and MOD11C3. Zhang et al. (2013a) proposed the classification scheme of drought based on VSDI. In addition to drought severity classes, VSDI can also distinguish water/land surfaces as shown in Table 3. Six drought severity classes were originally proposed; however, this study merges the first two classes (Extreme and Exceptional droughts) so that one can have five classes comparable with other indices in this study. 
Table 3: Classification of agricultural drought based on VSDI.

\begin{tabular}{lc}
\hline Drought severity class & VSDI \\
\hline Extreme/Exceptional drought & $<0.64$ \\
Severe drought & $\geq 0.64$ \\
Moderate drought & $\geq 0.68$ \\
Abnormally dry & $\geq 0.71$ \\
No drought (Normal) & $\geq 0.75$ \\
Water/Snow & $>1$ \\
\hline
\end{tabular}

\subsubsection{Temperature-Vegetation Dryness Index (TVDI)}

TVDI was proposed by Sandholt et al. (2002) as a soil moisture index that utilizes vegetation and temperature information. Similar to VHI and VDI, this index is subjected to the vegetation-temperature space concept which assumes that a negative correlation exists between vegetation and temperature. TVDI has wide applications in different regions of the world. For example, Wang et al. (2004) evaluated TVDI over China and concluded that by combining temperature and vegetation, TVDI is more accurate in monitoring soil moisture than Crop Water Stress Index (CWSI) which is solely dependent on temperature. Holzman et al. (2014) utilized TVDI to predict crop yield 1-3 months before harvest in Argentina. This index has also played role in drought monitoring in the Mekong River (Son et al., 2012), western India (Dhorde \& Patel, 2016), and northwest China (Zhang \& Bai, 2016).

To calculate TVDI, the pixel values of NDVI at each time step (1 month in this study) is plotted against the values of temperature. Given the nature of the relationship between vegetation and temperature, the scatter plot usually forms an approximate shape of a triangle (see Sandholt et al. (2002)). The NDVI-Temperature space is then divided into slices based on NDVI. In this study, 100 slices are formed at 0.01 intervals. For each slice, the maximum temperature, its corresponding NDVI value, and minimum temperature are recorded. Three lists of these variables are 
constructed depending on the number of slices. From the maximum temperature and its corresponding NDVI values, a linear regression model is developed, while the mean of the minimum temperatures is calculated. The linear regression model between NDVI and maximum temperature ( $\mathrm{LST}_{\max }$ ) forms the hypotenuse of the triangle, and the mean of minimum temperatures ( $\mathrm{LST}_{\min }$ ) forms the base of the triangle. Equation 2 then can be used to calculate TVDI.

$$
T V D I_{(i, j)}=\frac{L S T_{i, j}-\left(L S T_{\text {min }}\right)_{j}}{\left(L S T_{\max }\right)_{i, j}-\left(L S T_{\min }\right)_{j}}
$$

Where

$i$ is the spatial index for pixels from 1 to 17,212 .

$j$ is the temporal index for time steps in months from 1 to 161 .

$L S T_{\max }$ is the dry edge and is equal to $\left(a_{j}-N D V I_{i, j} \times b_{j}\right)$, and $L S T_{\min }$ is the wet edge.

$a$, and $b$ represent the linear regression coefficients for the $j^{\text {th }}$ time step.

Each time step has only one value of $L S T_{\text {min }}, a$, and $b$, while $L S T_{i, j}$ and $N D V I_{i, j}$ vary temporally and spatially. Then, TVDI is calculated for each pixel at each time step, and it ranges from 0 to 1 where 1 is the dry edge at which the soil is in the driest condition and no evaporation is occurring; and 0 is the wet edge where moisture supply to the soil is unlimited and evaporation is occurring at maximum rate (Sandholt et al., 2002). The data required for calculating TVDI is the same as VHI. Following Cao et al. (2014), TVDI can be classified as shown in Table 4. 
Table 4: Classification of agricultural drought based on TVDI.

\begin{tabular}{lc}
\hline Drought severity class & TVDI \\
\hline Extremely dry & $\leq 1$ \\
Dry & $\leq 0.8$ \\
Normal & $\leq 0.6$ \\
Wet & $\leq 0.4$ \\
Extremely wet & $\leq 0.2$ \\
\hline
\end{tabular}

\subsubsection{Masking Vegetation}

Since we are targeting agricultural drought in this study, each of the above indices is masked to vegetative areas, because these indices are designed to monitor vegetation in the first place and misleading results might occur if non-vegetated areas are included.The produced indices were also examined (not shown) and they showed that desert area always demonstrates drought condition. Apparently, agricultural drought indices that mainly monitor vegetation and moisture, indicate a constant drought condition in the desert area encompassing about $39 \%$ of the total area in Iraq (Omer, 2011).

In order to isolate vegetative areas, $\mathrm{MCD} 12 \mathrm{C} 1$ product is utilized. The product is provided annually at 0.05 degree spatial resolution. The land cover dataset of 2002 is used and University of Maryland (UMD) type 2 classification scheme is chosen following Ahmadalipour et al. (2017b). For masking purposes, all vegetation classes are combined together and isolated from other non-vegetated classes (e.g., urban areas).

\subsubsection{Precipitation}

The response of VDI and VHI with rainfall is examined in this study. Precipitation data are obtained from the Global Land Data Assimilation System (GLDAS): Noah land surface model version 1 monthly data with 0.25 X 0.25 degree spatial resolution (Rodell et al., 2007). Because of the difference in spatial resolution between 
rainfall and both VHI and VDI, the latter ones are resampled to match the rainfall data and Spearman correlation coefficient is calculated spatially over each pixel.

\subsection{Results and Discussion}

Agricultural drought is quantified in this study by comparing the areal coverage of drought severity classes over the years for the vegetated area in Iraq. In this study, we defined a drought year as any year where "No drought" condition is not spatially dominant. We choose April as the representative month of the year because it is the time of the year corresponding to the end of the growing season where vegetation is at peak. In addition, April has a prevailing clear sky condition which reduces uncertainty in the results (see section 2.1.3).

VHI and VDI demonstrate similar results to some extent by characterizing 2008 as a drought year as shown in Figure 5 and Figure 6. However, the drought severity level is different between the two. VHI shows that 2008 was dominated by moderate drought while VDI shows severe drought as the prevailing drought class.

In 2012, VHI shows that about 55\% of vegetated area is experiencing either mild or moderate drought, while VDI on the other hand shows that mild or moderate drought is dominant in 2009, 2011, and 2012 by $44 \%, 50 \%$, and $48.5 \%$ respectively. For both VHI and VDI, all other years are either dominated by no drought condition or are equally distributed between no drought and mild/moderate drought classes. Other than 2008, severe or extreme drought is not dominant in any year; in fact, these two classes are at minimal areal coverage in general.

VHI and VDI are compared with precipitation data in order to examine their accordance with rainfall. Both indices show a good agreement with precipitation, with VHI in the lead as shown in Figure 7. The resulted agreement with precipitation is achieved with no lag time between vegetation and precipitation. Although the results might give an indication of immediate response of vegetation to precipi- 


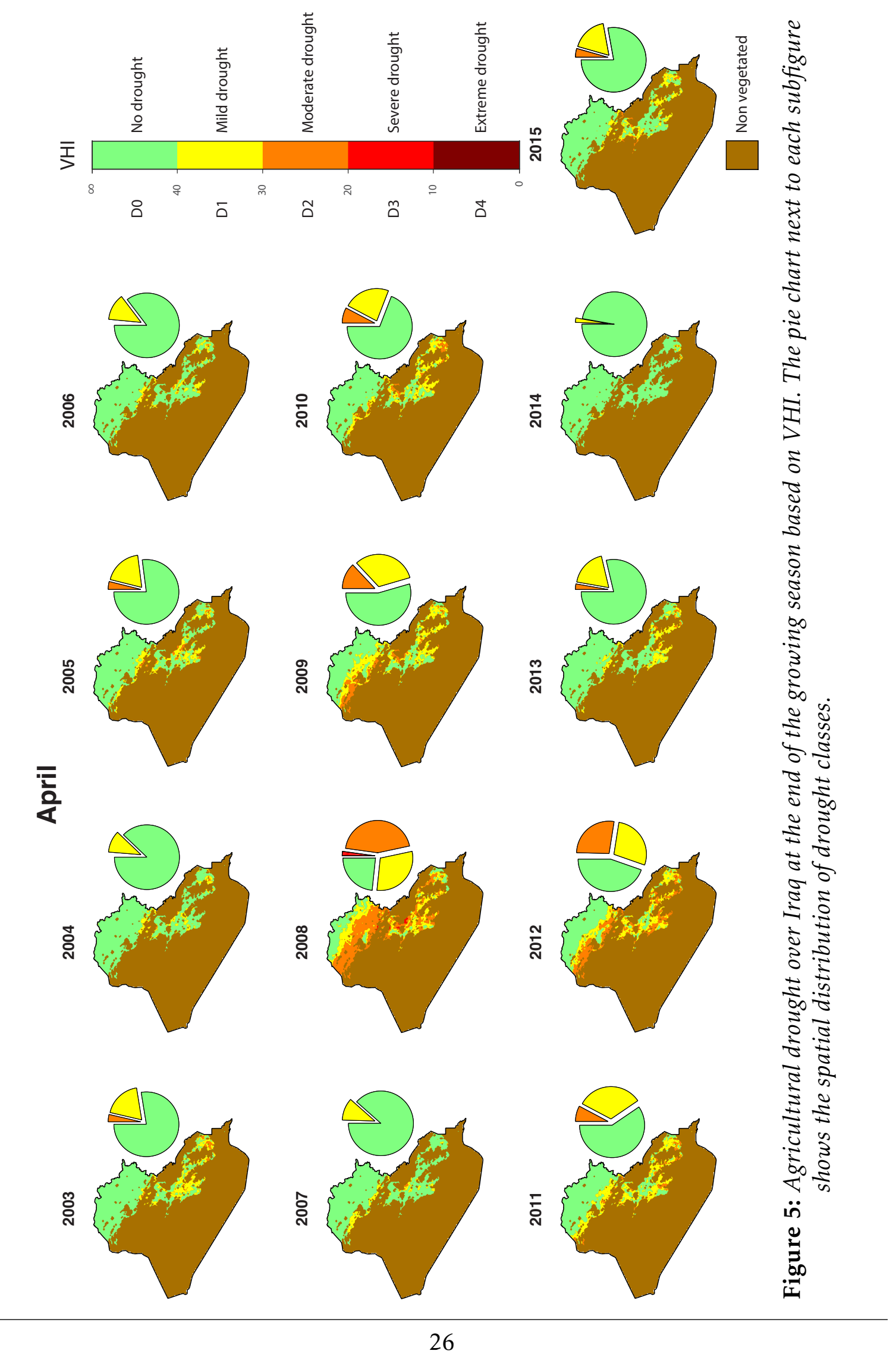




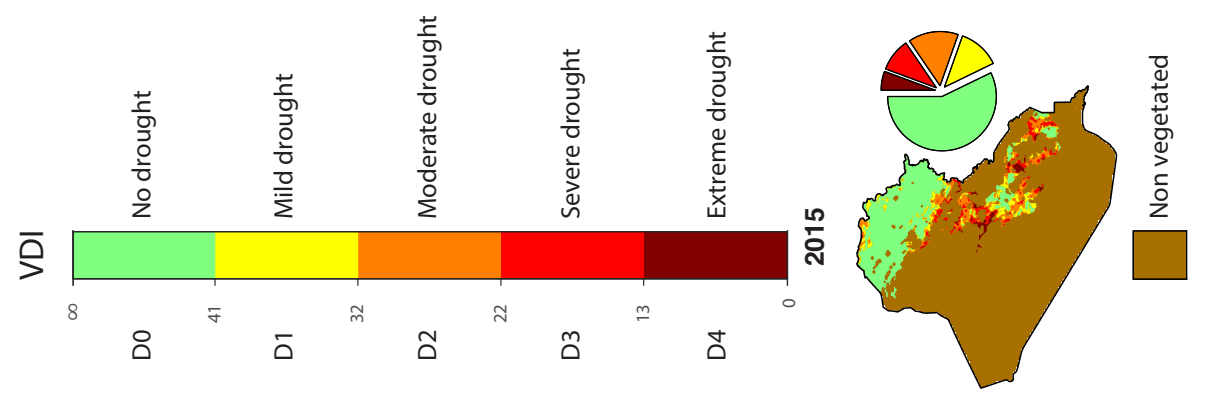

列
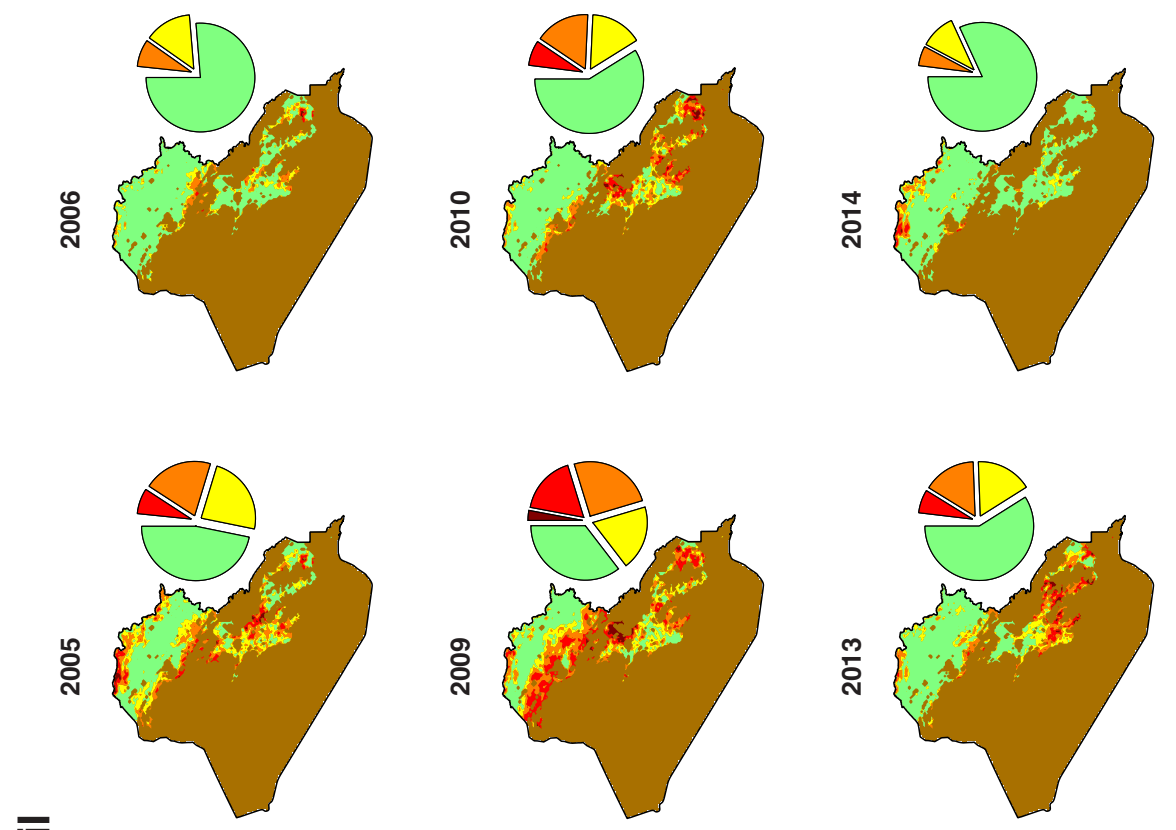

言
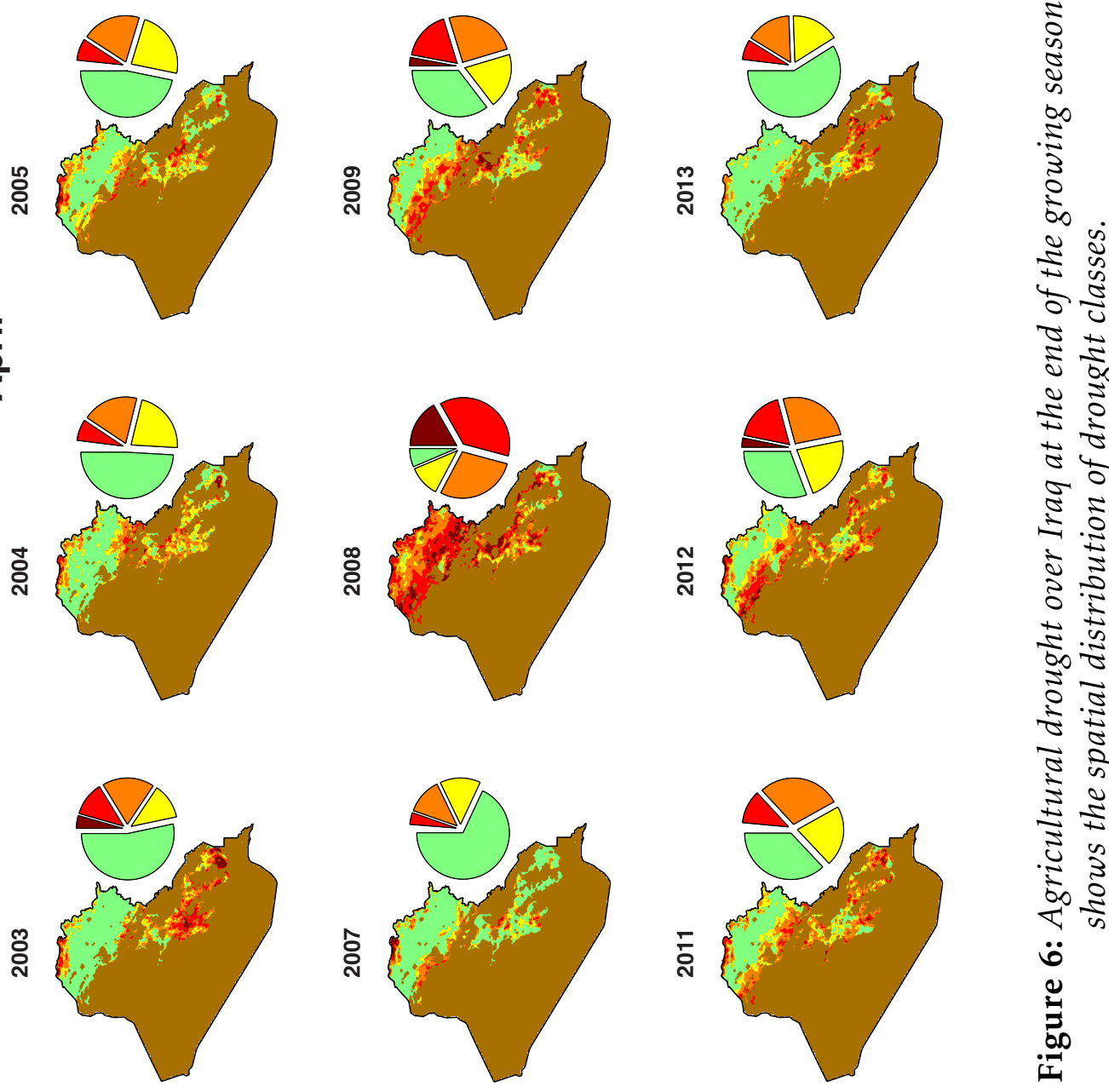
tation, it is not always true. Iraq is known to have rainfed farming in the northern parts and irrigated farming system in the middle and southern parts of the country (Hussein et al., 2016; Omer, 2011; Schnepf, 2003). This is clearly shown on the correlation distribution in Figure 7, where southern parts are less correlated with vegetation than northern parts.
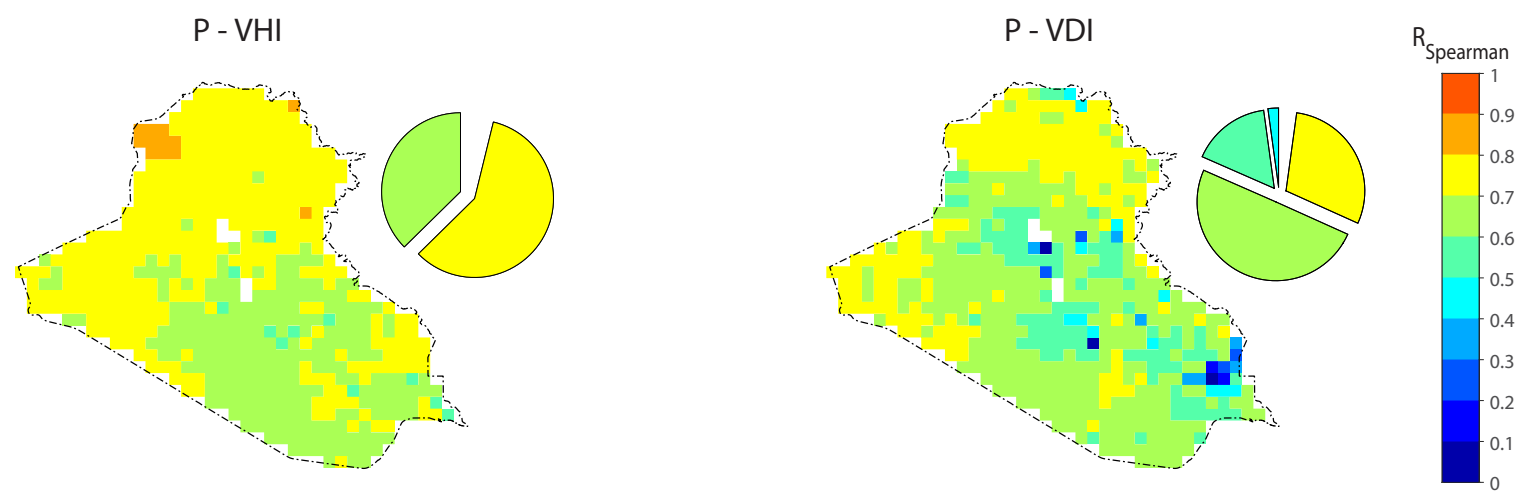

Figure 7: Spearman correlation coefficient between VHI and precipitation (left side) and VDI and precipitation (right side) for the study period (161 months). The pie chart next to each subfigure shows the spatial distribution of correlation classes.

However, each index is tested for meeting its assumptions by calculating the Spearman correlation coefficient between its components. As mentioned previously, VHI assumes a negative relation between NDVI and LST. Similarly, VDI assumes negative relationship between NDWI and $\Delta$ LST. If positive relation is found in the study area, then we should expect uncertainty introduced in the drought results. For this purpose, the correlation analysis is conducted over three periods: on January, a month in middle of the growing season, for the growing season, and for the whole period of study (Figure 8). It is clearly shown that VDI has outperformed VHI in terms of meeting the assumptions, which makes VDI more reliable than VHI in monitoring drought over Iraq. 

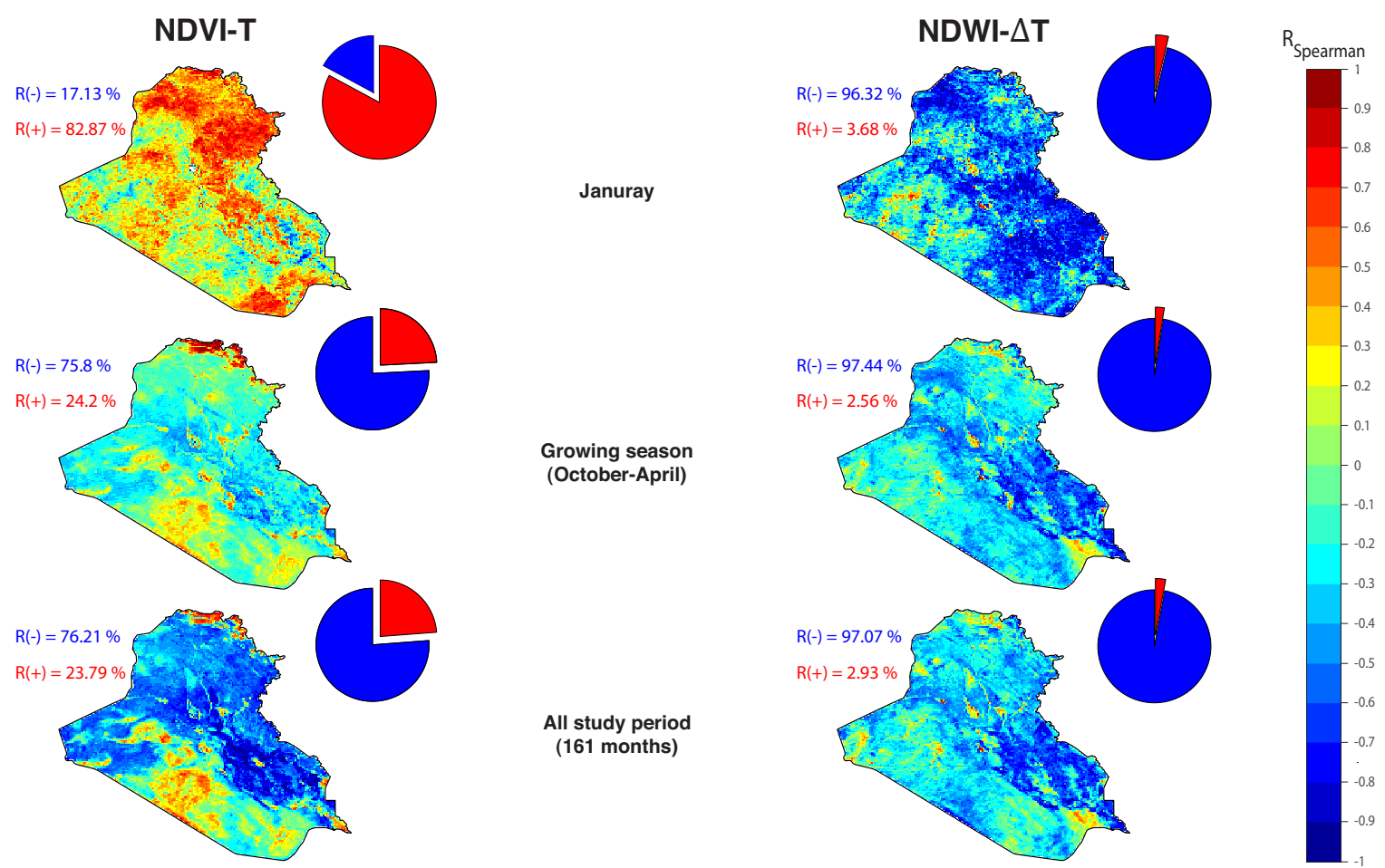

Figure 8: Spearman correlation coefficient between VHI components (NDVI and temperature on the left side) and VDI components (NDWI and temperature difference on the right side). The pie chart next to each subfigure shows the distribution of negative correlation (blue) and positive correlation (red), while the text next to each subfigure represents the percentage of positive and negative correlations in that subfigure.

VSDI, on the other hand shows that 2008, 2009, 2012, and 2013 are dominated by extreme/exceptional drought, while abnormally dry severity class is dominant in 2005 (see Figure 9). All other years had the normal condition as the prevailing class. Although these years are dominant by normal condition, abnormally dry and extreme/exceptional drought classes also show significant portions of areal coverage where each of these classes cover around $20 \%$ of the vegetated area. In general, VSDI presents more intense severity classes than VHI and VDI, and this result can be attributed to two factors: the nature of the data incorporated in VSDI and its resolution. As mentioned in section 2.1.3, VSDI is dependent on spectral bands in vegetation monitoring without incorporating temperature in 

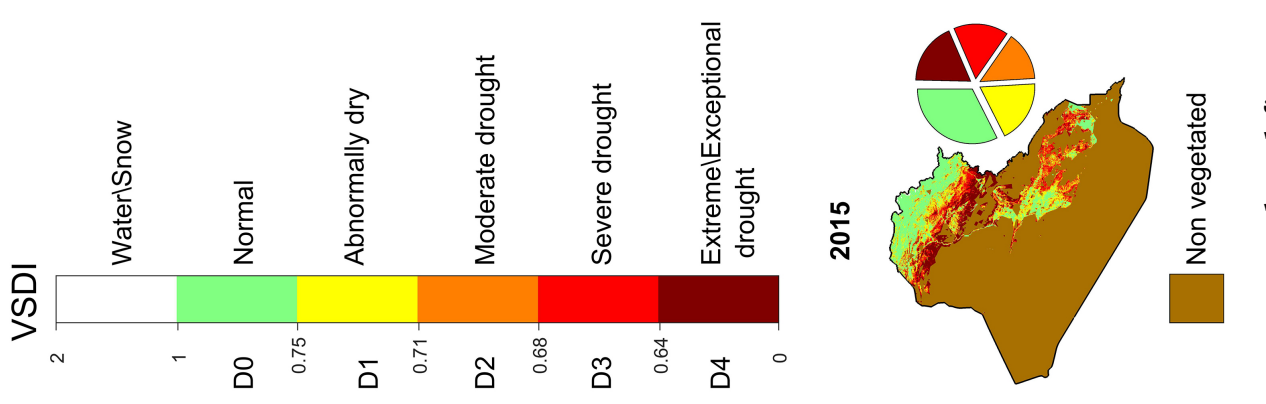

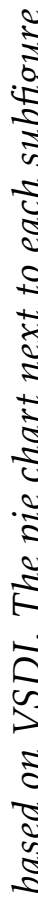
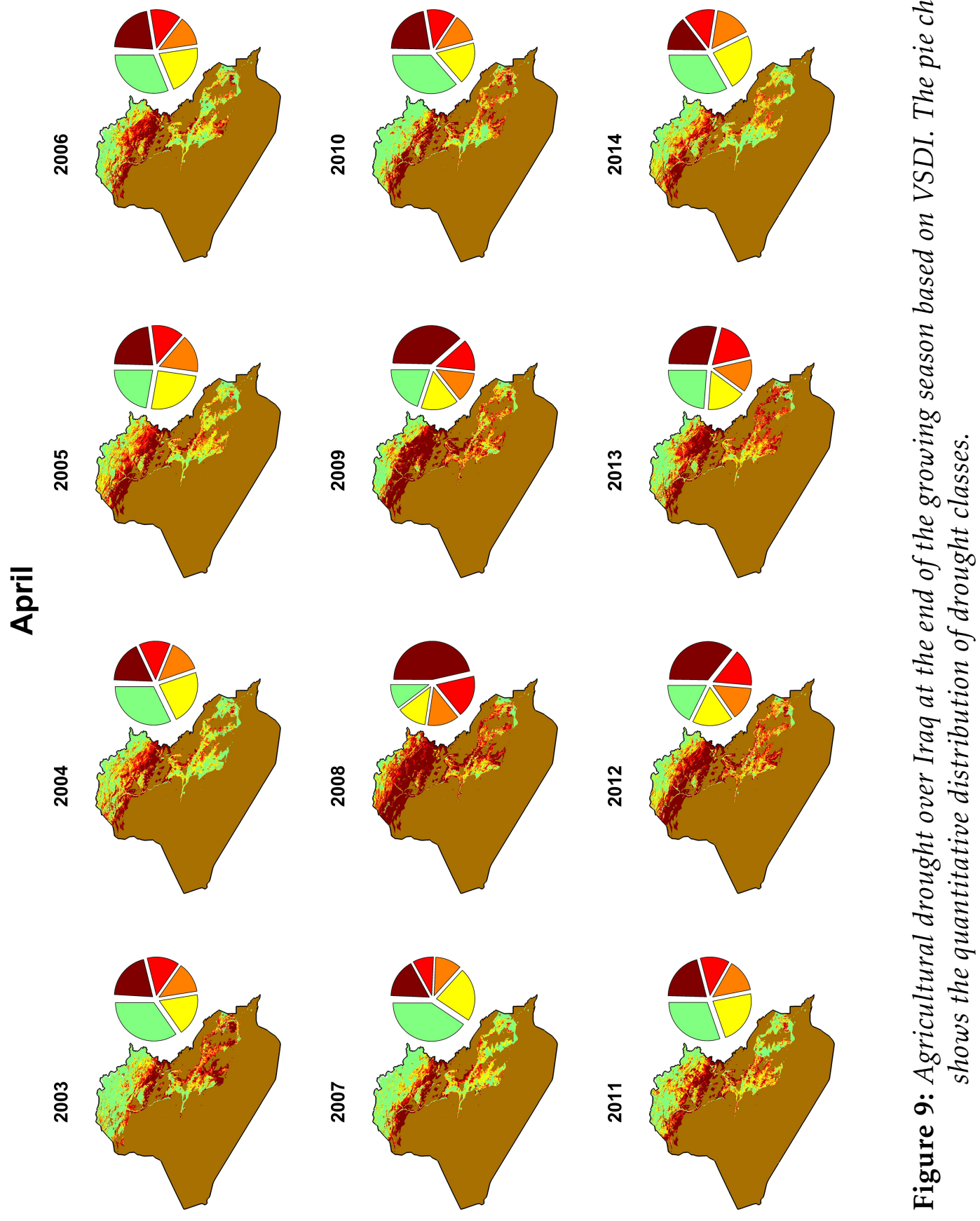
its calculation. This might be the reason that VSDI showed high values in this study, knowing that temperature has played as a quality control factor in drought monitoring using VHI, and VDI (see section 2.1.1). Unlike other indices in this study, VSDI uses 8-day composites in its calculation instead of monthly data, which means that data variability is higher than other indices. This conclusion is reached by the fact that data with smaller temporal scale shows higher variability than larger temporal scale (Guijarro, 2014); and averaging the data is basically smoothing it depending on the averaging window (Brown \& Mac Berthouex, 2002; Langbein, 2006). It is expected that spatial resolution of VSDI also affects the results since it is finer than other indices. These facts lead to the perception that extreme values are relatively suppressed in other indices by larger spatial and temporal resolutions. Another factor which is less likely to happen is the cloud contamination. It has been clarified previously that VSDI is less effected by the cloud cover than other indices in this study. This merit might be the reason that VSDI showed a more severe drought conditions than VHI and VDI. However, this factor is uncertain due to the fact that Iraq has a clear sky condition prevailing in April (Ahmad et al., 1983).

Although TVDI has wide applications in soil moisture monitoring, it has limitations that may affect its performance, and several studies have addressed these limitations. For example, Kimura (2007) highlighted that defining dry and wet edges in TVDI has an empirical nature because NDVI-Temperature space is dependent on the size of study area, and in order to define dry and wet edges correctly, a large study area need to be investigated so that it covers moisture extremes for a wide variety of vegetation surfaces. TVDI assumes that air temperature is constant over the investigated area which is not true and introduces uncertainty in the results, in addition to the fact that heterogeneity of earth's surface amplifies 
TVDI uncertainty (Rahimzadeh-Bajgiran et al., 2012; Srivastava et al., 2016). On the contrary to Kimura (2007), Rahimzadeh-Bajgiran et al. (2012); and Srivastava et al. (2016) suggested the application of TVDI on small scale areas where variation in air temperature and earth surface heterogeneity (e.g., topography) are less. Garcia et al. (2014) investigated TVDI accuracy and concluded that TVDI showed more accurate results in water-limited regions than energy-limited ones and suggested the usage of daily data instead of 8-day composite data for TVDI calculation.

As a soil moisture index, TVDI do not have the capability to distinguish specific drought events. In fact, TVDI shows that all years in the study period experienced either dry or extremely dry conditions (Figure 10). This poor performance might be due to the multiple limitations mentioned previously. In addition to the fact that TVDI depends on vegetation-temperature space concept represented by NDVI and LST, which has been shown to be not accurate over Iraq (see Figure 8).

In order to test the validity of each of the aforementioned indices, we compare the results with the findings of other studies, as we are trying to employ remote sensing to monitor agricultural drought over data-inaccessible region. This comparison is a challenge by itself due to the fact that agricultural drought has not been targeted yet on a nationwide scale as mentioned in section 1.2.1. A study was conducted by Trigo et al. (2010) over the Fertile Crescent area, utilized NDVI and showed that northern part of Iraq experienced a persistent pattern of vegetation stress for 6 months in 2008 and 5 months in 2009. The same study highlighted a degradation in total cereal production in those years. 


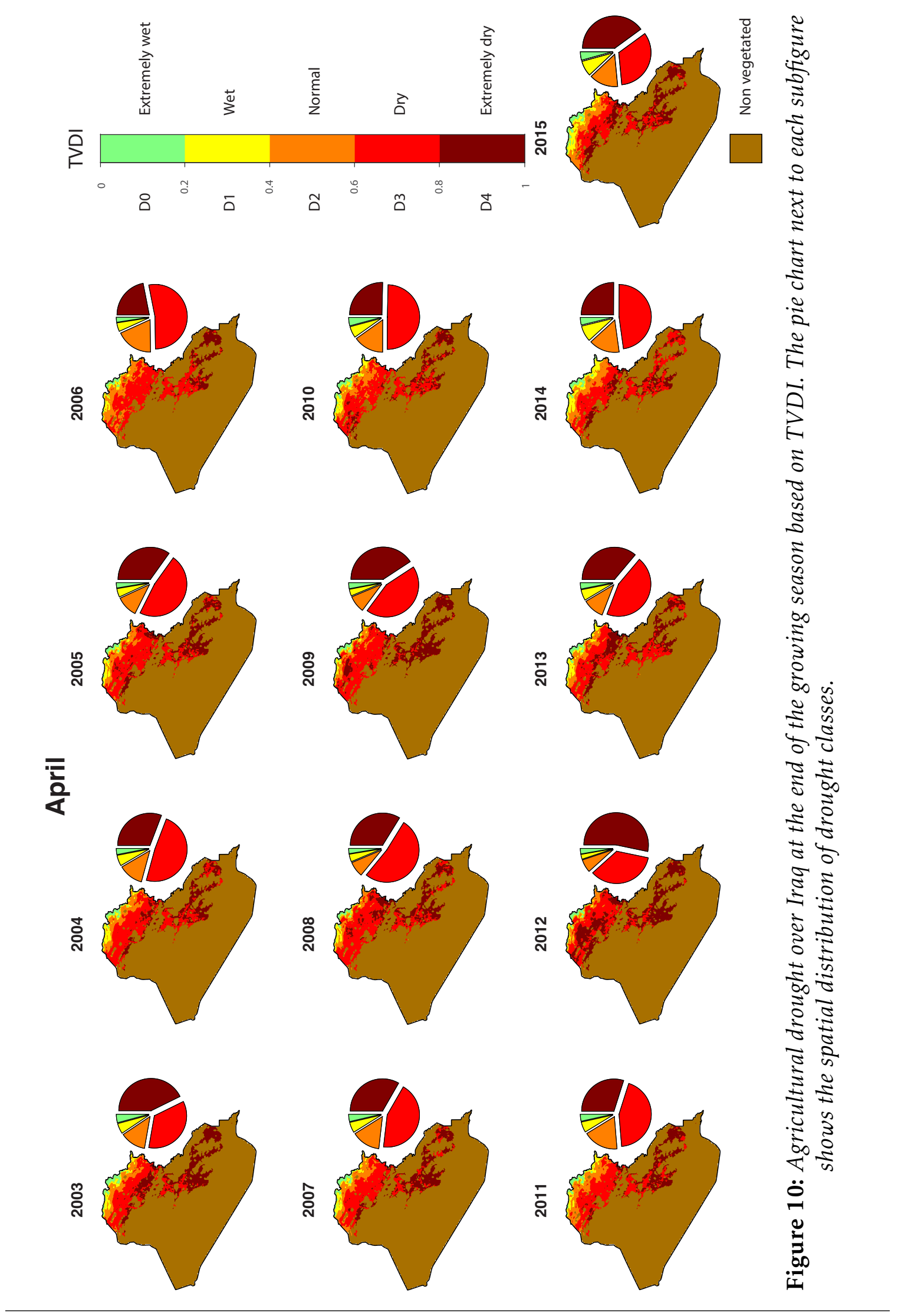


Total cereal production degradation was also observed by the FAO statistics database downloaded from (http://faostat.fao.org), where the recession in cereal production was also observed in 2012 as shown in Figure 11.

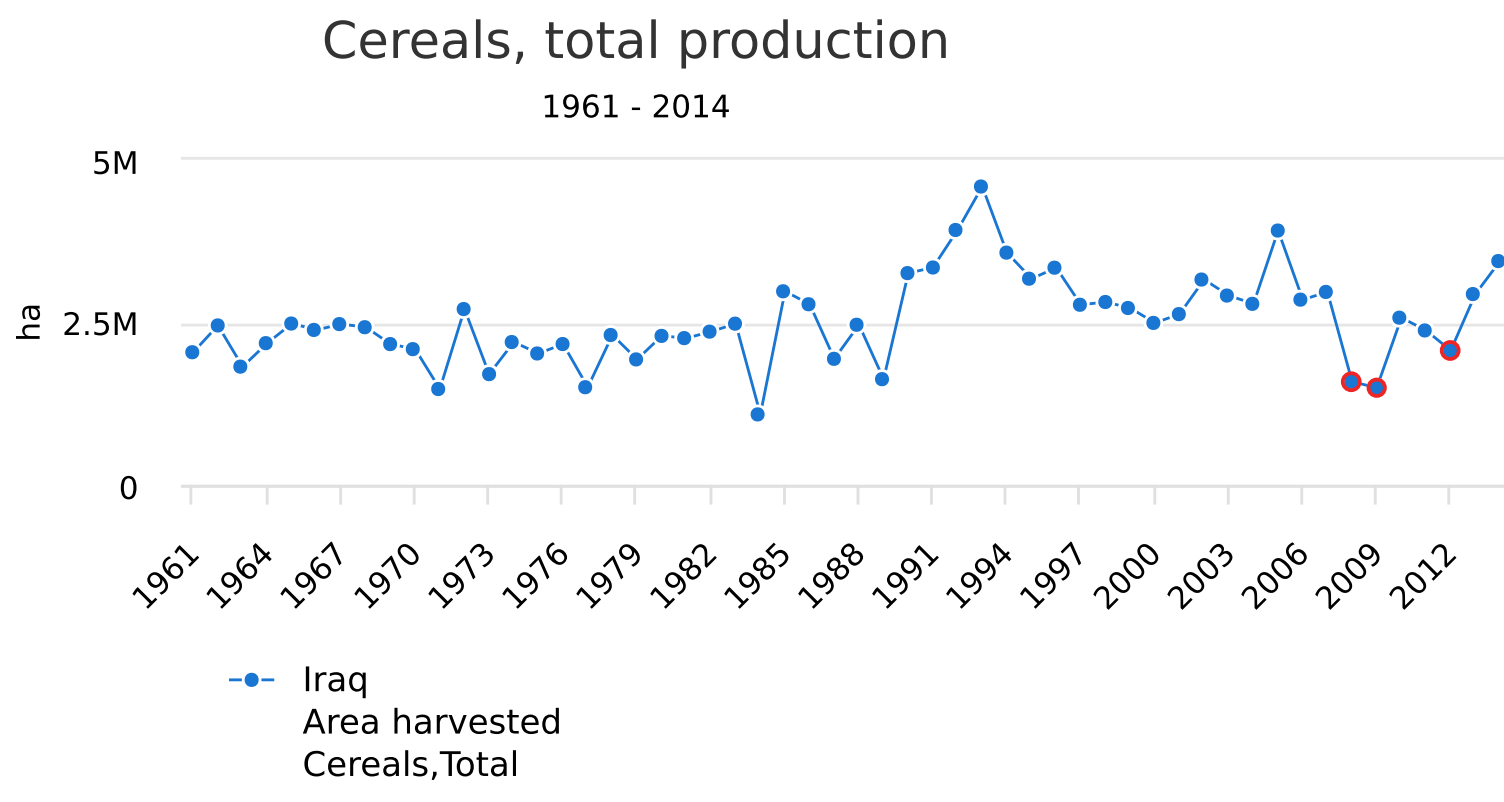

Figure 11: Total cereals production in Iraq from $F A O$ statistical database (http: / / faostat.fao.org). Red circles highlights years with reduced production in the study period.

Based on SPI, three evident droughts took place in 2006, 2008, and 2009, where the last two droughts caused about $40 \%$ loss for the cropland, especially in the northern part of Iraq (UNESCO, 2014). That report pointed that a major declination in vegetation cover occurred between 2009 and 2012 especially in Diyala, Salah al Din, and Basrah governorates where the vegetation cover loss was estimated at $65 \%, 47 \%$, and $41 \%$ respectively.

Comparing these results with the findings of this study, it is seen that VSDI and VDI are more applicable over Iraq than other indices introduced in this study. Unlike VHI and TVDI, they are capable of detecting the 2008-2009 drought event which has been confirmed by other studies. Also, both of these indices identified 
2012 as a drought year which coincides with the findings of UNESCO (2014), and FAO statistics database. However, the only difference between VDI and VSDI results is that VDI highlighted 2011 as a drought year while VSDI identified 2013 and 2005 instead. This difference might be attributed to the difference in the input data and calculation methodology of each index. Since no other studies over Iraq have addressed agricultural drought in this manner, it is a difficult task to decide which of these two indices is more accurate in this phase, but we speculate that VDI is more suitable than VSDI for Iraq because of temperature integration in its calculation, a main factor that plays a vital role in vegetation condition and climatic variables. In accordance with Zhang et al. (2013a), we believe that VSDI is able to detect major drought events, but on the other hand it has overestimated drought severity due to the lack of temperature factor in its structure which led to VSDI underperformance in comparison with VDI. 


\section{Chapter Three: Hydrological Drought}

\subsection{Data and Methods}

\subsubsection{Data}

\subsubsection{Terrestrial Water Storage (TWS)}

GRACE measures the change in earth's gravity periodically where measured gravity signal is obtained on a monthly basis and represents a reflection of the changes in earth's mass over different regions (Wahr et al., 2006). They also pointed out that mass movement can be subdivided into three compartments: atmospheric signal, ocean signal, and land signal. GRACE products are produced in three processing centers: CSR (U. Texas / Center for Space Research); GFZ (GeoForschungsZentrum Potsdam); and JPL (Jet Propulsion Laboratory), these centers provide Level-2 data in the form of spherical harmonic fields of earth's gravity field (Bettadpur, 2012; Meyrath \& van Dam, 2016). Level-2 data are available in two generations: Release04 and Release-05, where the latter is the latest, and showed an improvement over Release-04 (Chambers \& Bonin, 2012). In this study, we are using the latest Level-3 Release-05 gridded GRACE data found in GRACE-Tellus website, provided by CSR (http://grace.jpl.nasa.gov), and derived from Level-2 data.

The data is available on a monthly basis as GeoTiff files gridded at $1 \times 1$ degree spatial resolution and covers the globe. The retrieved data from GRACE Tellus website was already preprocessed to reflect land signal only; this includes the replacement of degree 2 and order 0 spherical harmonic coefficients with the ones from satellite laser ranging (SLR) because the latter is more reliable (Cheng \& Tapley, 2004; Marti, 2014). Also, the spherical harmonic coefficients of degree 1 are not retrievable by GRACE, so they were estimated according to Swenson et al. 
(2008). Finally, the data was subjected to destriping ${ }^{1}$ filtering to minimize the effect of correlated errors that appears as N-S stripes in the monthly data, also, a $300 \mathrm{~km}$ wide Gaussian filter was applied to the data. A complete list of corrections and their details can be found in GRACE-Tellus land products data processing website (http://grace.jpl.nasa.gov/data/get-data/monthly-mass-grids-land/).

The final product is a monthly gridded data of equivalent water thickness in the ground as deviation from long-term mean referred to as Terrestrial Water Storage Anomaly (TWSA), and measured in centimeters. The temporal extent of the data is 161 months from August 2002 till December 2015. Several missing months are found and retrieved using linear interpolation following Guo et al. (2016), and Wang et al. (2011). The gridded data is then masked to the study area, and because GRACE product has a coarse spatial resolution, area weighting procedure is implemented to retrieve approximate signal of TWSA over Iraq as shown in Figure 12. For analyses in the next sections, all 161 records of gridded TWSA are spatially averaged over Iraq.

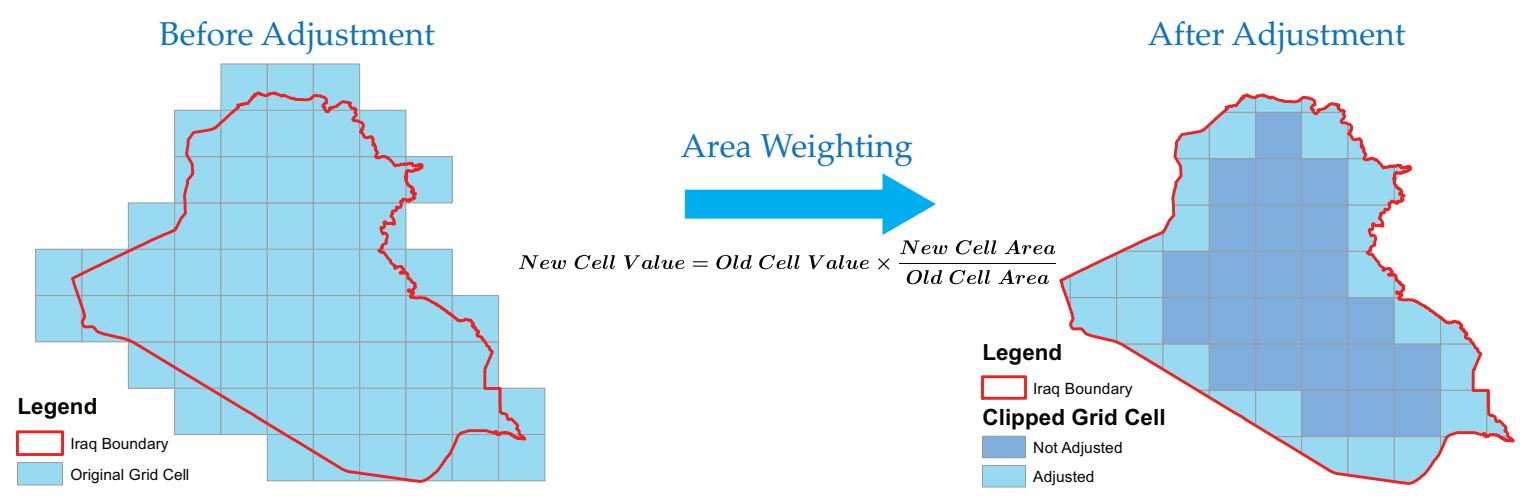

Figure 12: Area weighting of $1 \times 1$ degree grid cells on the boundary of the study area (light-blue colored cells on the right side of the figure).

\footnotetext{
${ }^{1}$ GRACE data have noise and systematic errors inherently. In order to extract useful data, a filtering process summarized by destriping and Gaussian filtering is required, which trims some of the spherical harmonic coefficients (Klees et al., 2008).
} 


\subsubsection{Methods}

\subsubsection{Drought Deficit}

Although this study follows the approach proposed in Thomas et al. (2014), the deficit as presented in Equation 3, is calculated slightly different from their approach. Thomas et al. (2014) defined the deficit as the negative residual of the difference between each month's TWSA and its own climatology (Equation 3), where the climatology defined as the long term mean of that specific month (e.g. mean of all Januaries during the study period). In this study, we define the deficit as the months with negative TWSA. In other words, we define deficit similar to Thomas et al. (2014), but by accounting for only the first term in Equation 3 as shown in Equation 4.

$$
\begin{array}{ll}
\text { Deficit }_{(i)}=T W S A_{(i)}-\text { Climatology }_{(j)} & \text { Where Deficit }<0 \\
\text { Deficit }_{(i)}=T W S A_{(i)} & \text { Where TWSA }<0
\end{array}
$$

Where $i$ ranges from 1-161 for each month, $j$ ranges from 1-12 for each month's climatology (long-term mean).

The reason behind this modification is due to the fact that GRACE provides only deviation from the mean values of terrestrial water storage, not the actual values. That is, the obtained observations considered as deficit or surplus, and referred to as anomaly. By subtracting climatology of anomaly from the anomaly itself, the physical meaning of the signal would be unclear. Equation 3 characterizes the deficit that is more than normal (mean) deficit defined by climatology. This fact leads to the negligence of the drought events that has deficit values less than normal, and shows incomplete picture of the hydrological drought. Also, it dissipates the actual deficit values observed by GRACE. Tallaksen et al. (2009) found that a 
hydrological drought event usually lasts 4-5 months. Based on these findings, a drought event is defined in this study as four consecutive months of deficit or more.

\subsubsection{Drought Severity}

Severity is defined as the combined effect of deficit magnitude and its persistence (Madadgar \& Moradkhani, 2013b; Thomas et al., 2014). The severity for month $i$ is calculated as the mean deficit from the onset of a drought up to the $i^{\text {th }}$ month multiplied by the number of months from the onset of the drought event up to the $i^{\text {th }}$ month. The aforementioned definition can also be expressed as the cumulative deficit from the onset of a drought event up to the specified month. Equation 5 expresses severity mathematically.

$$
\operatorname{Severity}_{(i)}=\sum_{1}^{i} \operatorname{Deficit}_{(i)}
$$

where $i$ represents the position of the month being calculated relative to drought onset. Severity is then measured in $\left(\mathrm{km}^{3}\right.$.month). The total severity of a drought event is the severity at the final month before drought termination.

\subsubsection{Drought Recovery}

Drought recovery is characterized based on simple statistical approach. Thomas et al. (2014) measured recovery speed by measuring how fast the deficit is changing with time. First, the rate of change of deficit is calculated based on Equation 6:

$$
\left(\frac{\Delta(\text { Deficit })}{\Delta t}\right)_{(i)}=\frac{\text { Deficit }_{(i)}-\text { Deficit }_{(i-1)}}{t_{(i)}-t_{(i-1)}}
$$

Where $i$ ranges from 1 to 161 months for the study period. The initial rate of change is considered zero. Also, the denominator is always equal to 1 given that the time 
interval is equal to 1 month.

The second step is to estimate the normal and high values for the rate of change of deficit. These values will be used later to estimate time of recovery for months with drought conditions. Kaplan-Meier ECDF is utilized here by isolating the rate of change of deficit values corresponding to the $68^{\text {th }}$ and $95^{\text {th }}$ percentiles as shown in Figure 13.

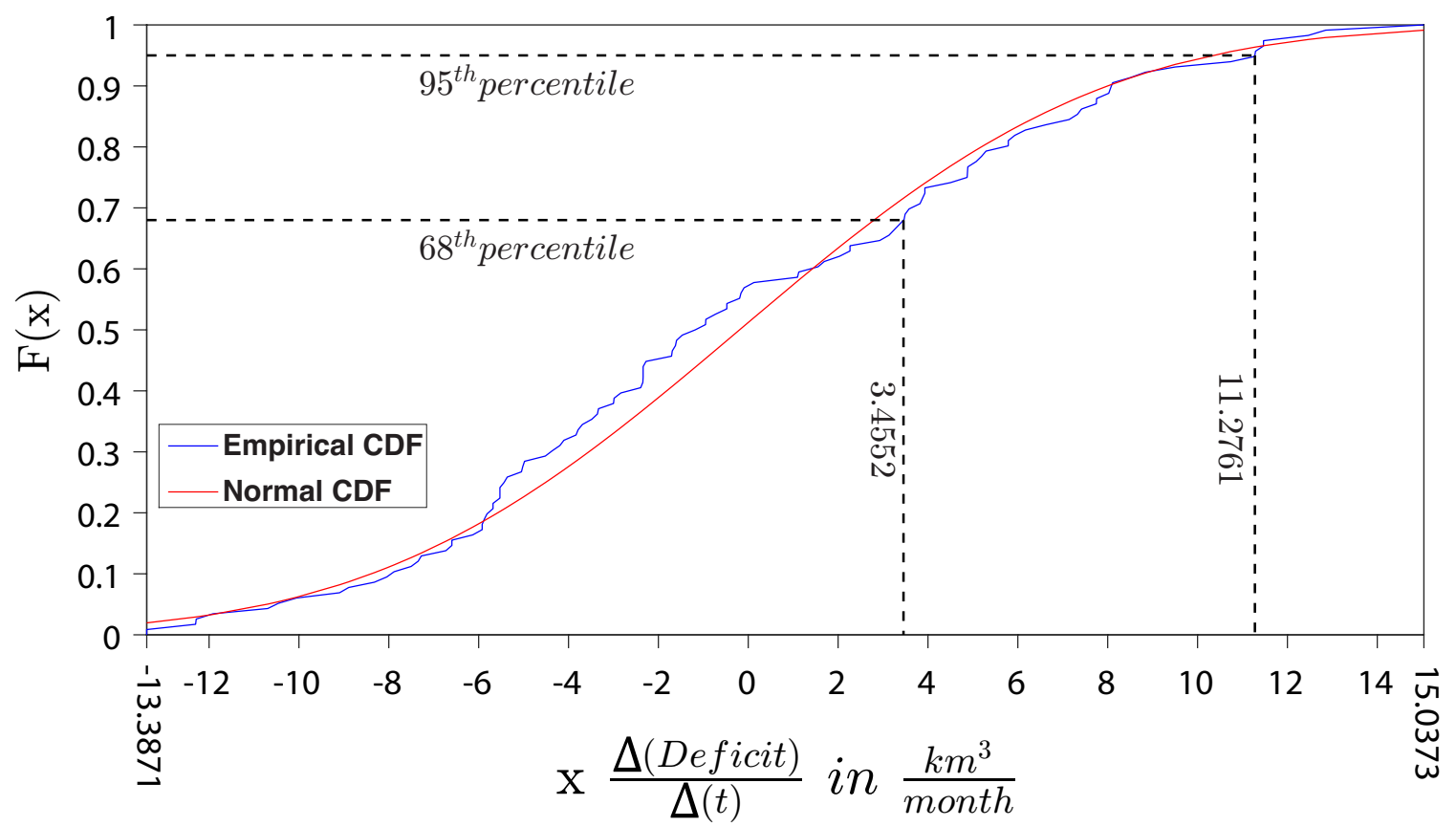

Figure 13: The empirical cumulative distribution function of the rate of change of deficit. Dashed lines highlights the $68^{\text {th }}$ and $95^{\text {th }}$ percentiles.

Recovery time for each month is estimated in two categories: the normal time to recover and the minimal time to recover. Both time categories are computed by dividing each month's deficit by the normal value ( $68^{\text {th }}$ percentile), and the high value ( $95^{\text {th }}$ percentile) of rate of change of deficit (Equation 6) derived from the ECDF in the previous step.

The statistical approach in this study is verified by a direct mathematical approach proposed by Parry et al. (2016). First, recovery event should be defined 
similar to the drought event (see section 3.1.2.1) by setting the limits required for a drought event to recover. The purpose of these limits is to prevent minor surpluses from breaking a major drought event into smaller drought events. Here, we considered a drought event to be recovered if it is followed by three consecutive months of surplus or more. The rate of recovery is estimated as the slope of the line connecting the peak of the drought event and the third consecutive month of surplus, while the recovery time is estimated as the horizontal projection of the sloped line.

\subsubsection{Classification}

The Total Storage Deficit (TSD) can be computed following Yirdaw et al. (2008). First, each month's mean, maximum and minimum anomaly is computed, then Equation 7 is applied as follows:

$$
T S D_{(i)}=\frac{T W S A_{(i)}-\operatorname{Mean}\left[T W S A_{(j)}\right]}{\operatorname{Max}\left[T W S A_{(j)}\right]-\operatorname{Min}\left[T W S A_{(j)}\right]} \times 100
$$

Where TWSA is the monthly terrestrial water storage anomaly, $i$ ranges from 1 to 161 for all months during the study period, and $j$ ranges from 1 to 12 representing the mean, maximum, and minimum anomalies for each month of the year. TSD is used as an input in Equation 8 with other factors to compute Total Storage Deficit Index (TSDI) as follows:

$T S D I_{(i)}=p \times T S D I_{(i-1)}-q \times T S D_{(i)}$

Where:

$p=1-\frac{m}{m+b}$

$q=\frac{C}{m+b}$ 
$m, b$, and $C$ are factors derived from the drought monograph (page 42), and $T S D I_{(1)}=0.02 \times T S D_{(1)}$ (Yirdaw et al., 2008). TSDI classification schemes have been discussed in Awange et al. (2016) and Cao et al. (2015). However, here we use the approach by Cao et al. (2015) because Awange et al. (2016) proposed detailed classification of positive TSDI values in their study which is not the case in this study. The classification thresholds are shown in Table 5 below:

Table 5: TSDI classification thresholds (Cao et al., 2015).

\begin{tabular}{lc}
\hline Class & TSDI value \\
\hline Wet & $T S D I>1$ \\
Near normal & $-1<T S D I \leq 1$ \\
Mild drought & $-2<T S D I \leq-1$ \\
Moderate drought & $-3<T S D I \leq-2$ \\
Severe drought & $-4<T S D I \leq-3$ \\
Extreme drought & $T S D I \leq-4$ \\
\hline
\end{tabular}

Drought monograph concept is explained in Palmer (1965). Here, we will describe the procedure used in Yirdaw et al. (2008). First, the cumulative of TSD (CTSD) is calculated, and the range of CTSD is divided into 4 parts. A line is drawn from $\mathrm{CTSD}_{(1)}$ to the boundary of each part. The assumption of this method is that $\mathrm{CTSD}=0$ line represents normal condition, and the four other lines (below CTSD $=0$ line) are deviations towards the worst condition. From here, we can define each line as a severity class depending on its deviation from the normal condition $(\mathrm{CTSD}=0)$. These lines are denoted from $C=-1$ to $C=-4$ from least sever to the severest drought condition (see Figure 14). Our objective is to find the closest line to CTSD line. In order to achieve this goal, some performance measures will be utilized as explained in section 3.2. After defining the closest line to CTSD, $m$ in Equation 9 and Equation 10 represents the slope of the line, $p$ is the intercept, and $C$ is the line severity degree between -1 and -4 . 


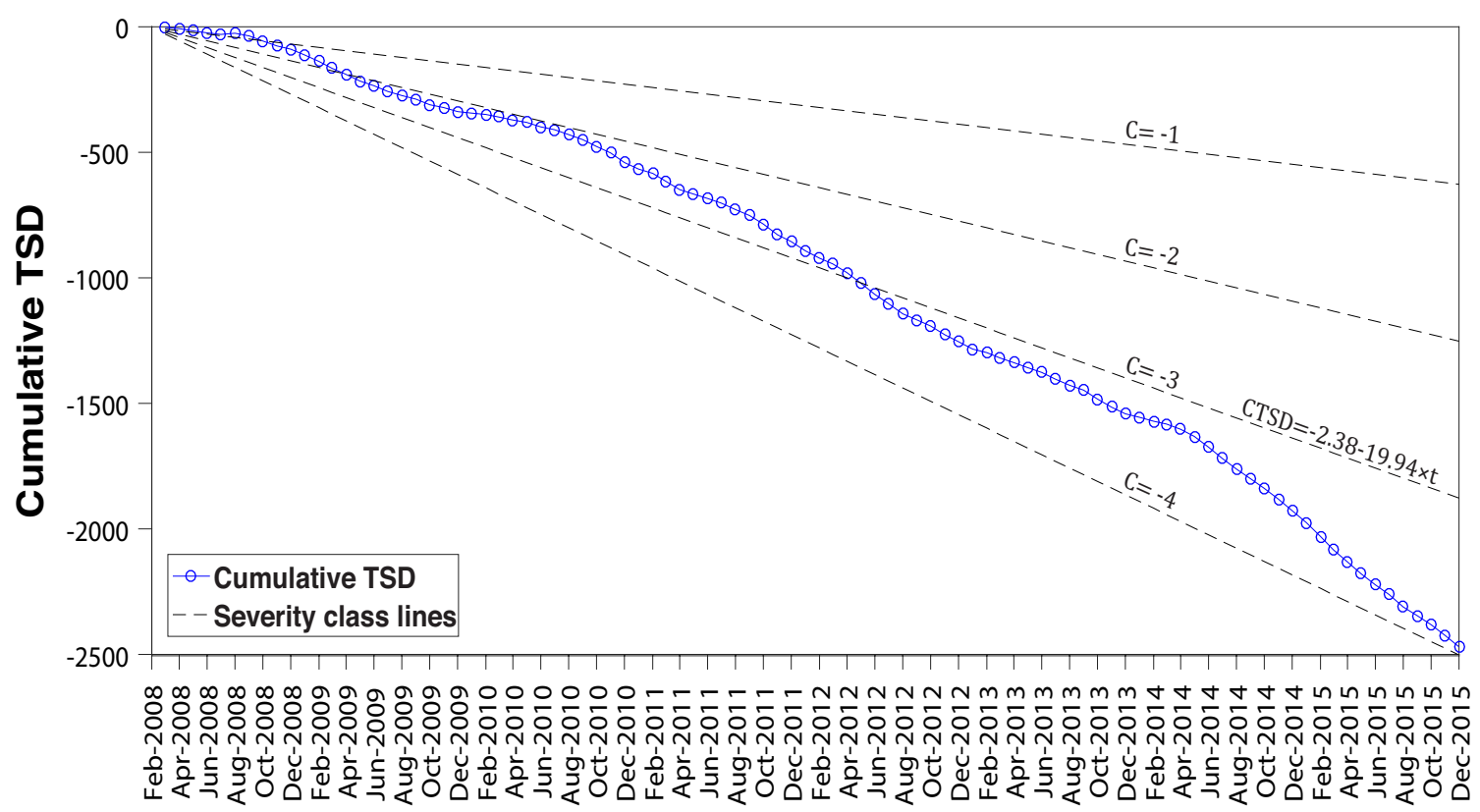

Time

Figure 14: Illustrates the drought monograph. $C=-1$ represents the threshold of least severe drought and $C=-4$ is the threshold for the severest drought.

\subsubsection{Trend analysis}

The same Precipitation, and Temperature datasets used in Figure 2 and section 2.1.6 are used in this analysis. After spatial averaging of Precipitation, Temperature, and TWSA datasets, Mann-Kendall test is utilized to evaluate the existence of a monotonic trend and its significance. The datasets are first tested for autocorrelation, and the results returned positive for all three. Therefore, a modified version of Mann-Kendall trend test proposed by Hamed and Ramachandra Rao (1998) is applied, which accounts for autocorrelation, and used to statistically verify the trends in the results section.

\subsection{Results and Discussion}

TWSA and deficit values are multiplied by the area of Iraq to reflect the volumetric change in TWSA, and the results are depicted in Figure 15. Figure 15a shows that the drought events before 2008 are not captured according to the approach by 
Thomas et al. (2014), and deficit magnitude is underestimated in comparison with the actual GRACE observation in Figure 15b. Four drought events are observed by GRACE TWSA and are summarized in Table 6. The first three drought events share the characteristics of short temporal extent and low deficit magnitude, on the other hand, the fourth drought event shows a persistent pattern and an increasing deficit from August 2007 till December 2015 (see Figure 15b, and Table 6). These results are in agreement with the findings of Chulov (2009), UNESCO (2014), and Voss et al. (2013), with a drought onset marked in 2007.

As mentioned before, drought events $<4$ months are not considered as significant events in this study. Also, an inter-drought surplus in TWSA $<3$ months are not considered enough for drought recovery. These assumptions are in line with those of Parry et al. (2016), Thomas et al. (2014), and Zhang et al. (2016), however, in these studies the constraints are area dependent and they aim to prevent minor changes in TWSA (e.g. deficit or surplus) from dividing major drought events into smaller ones or produce insignificant droughts. 
(a)

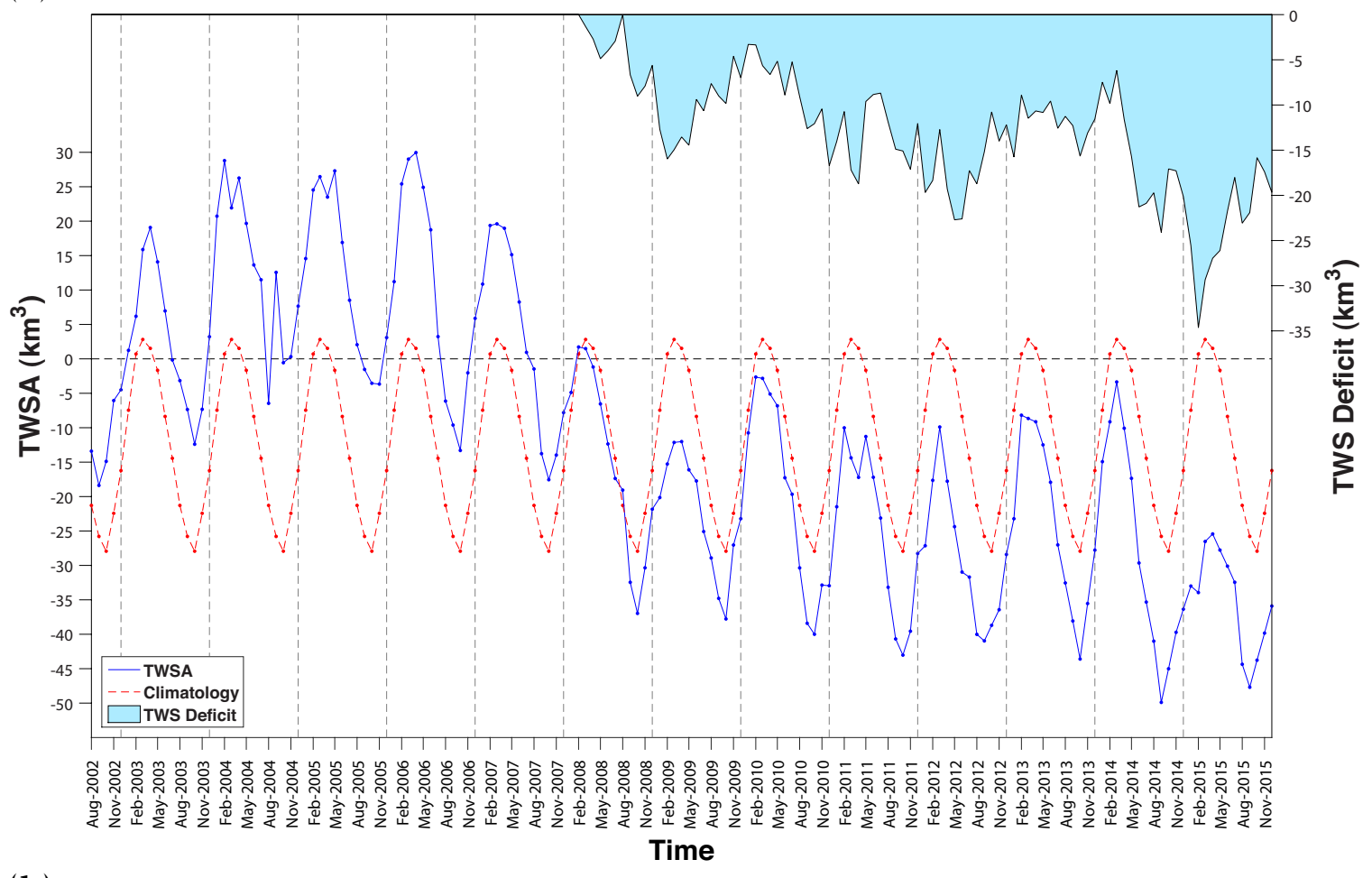

(b)

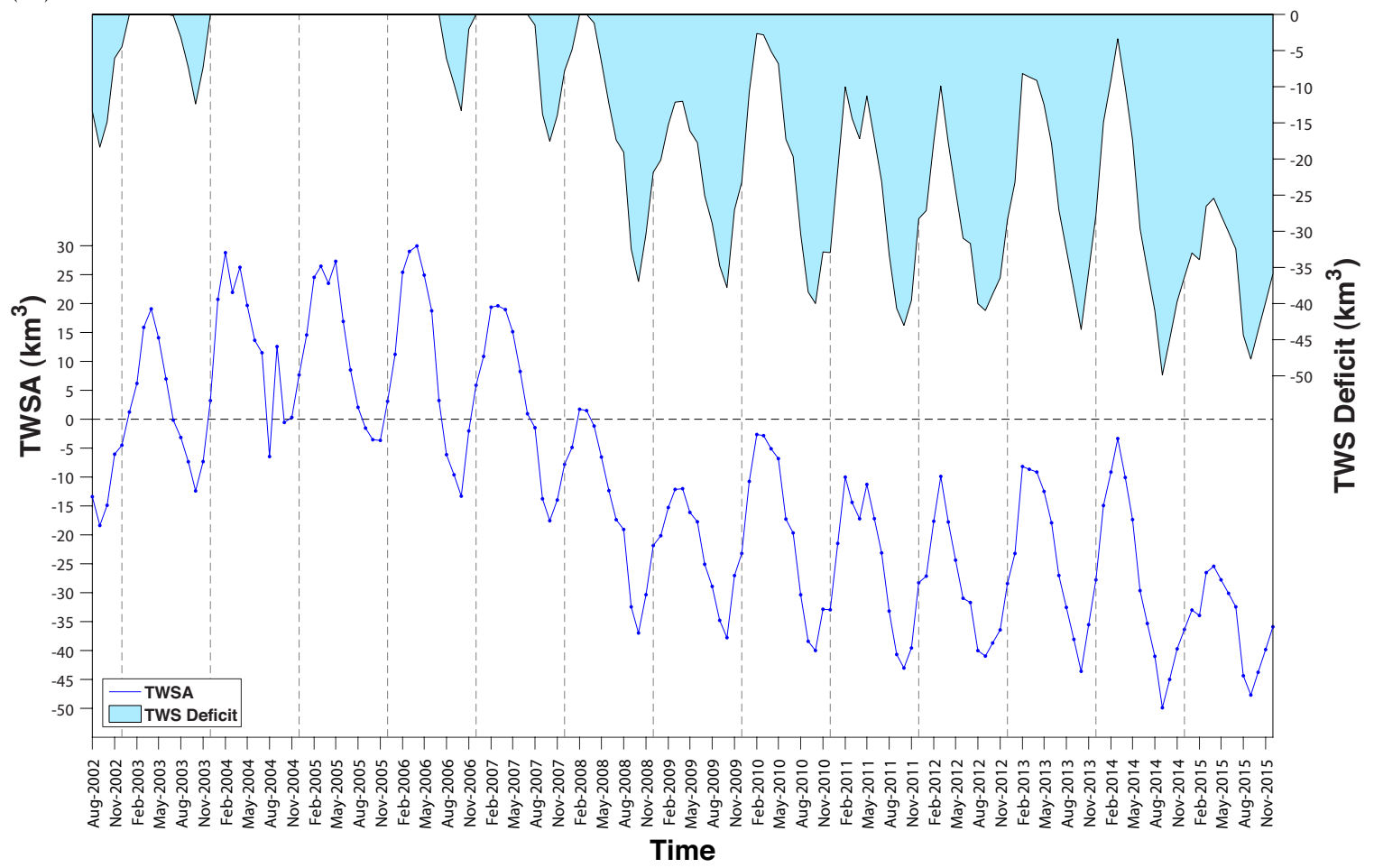

Figure 15: A comparison between (a) the deficit calculation in Thomas et al. (2014), and (b) the approach in this study. Vertical black dashed lines denotes the end of a calender year. 


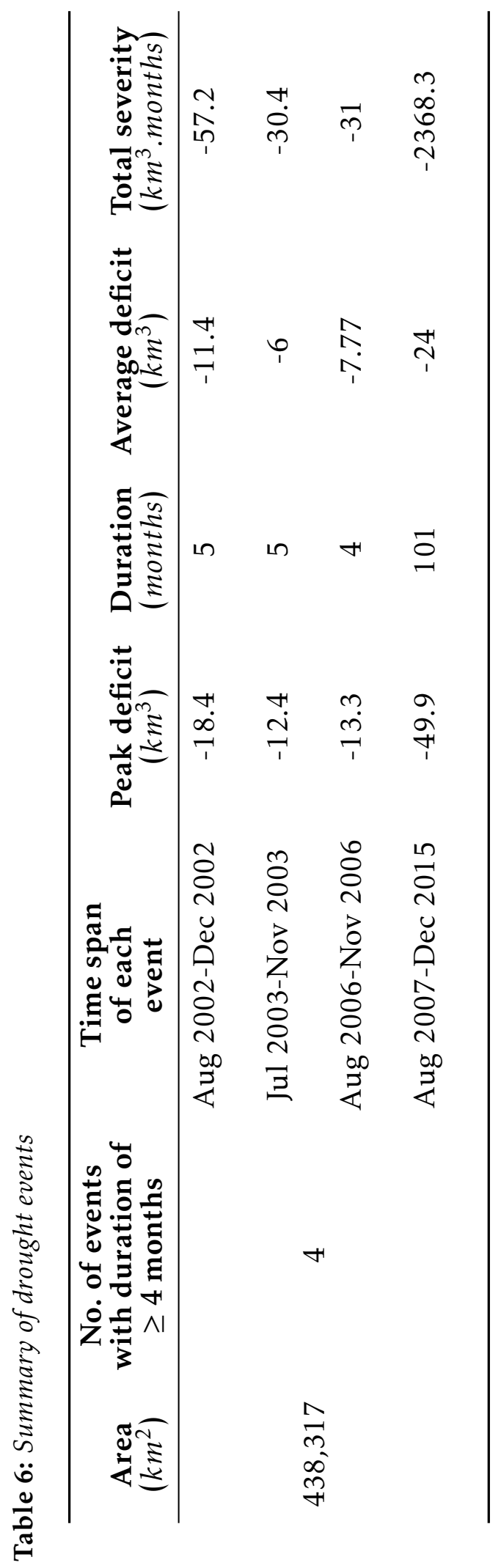


Similar to the long temporal extent and high deficit magnitude of the last drought event, the severity is by far higher than the first three droughts (see Figure 16) because of the fact that severity is the integration of deficit with time.

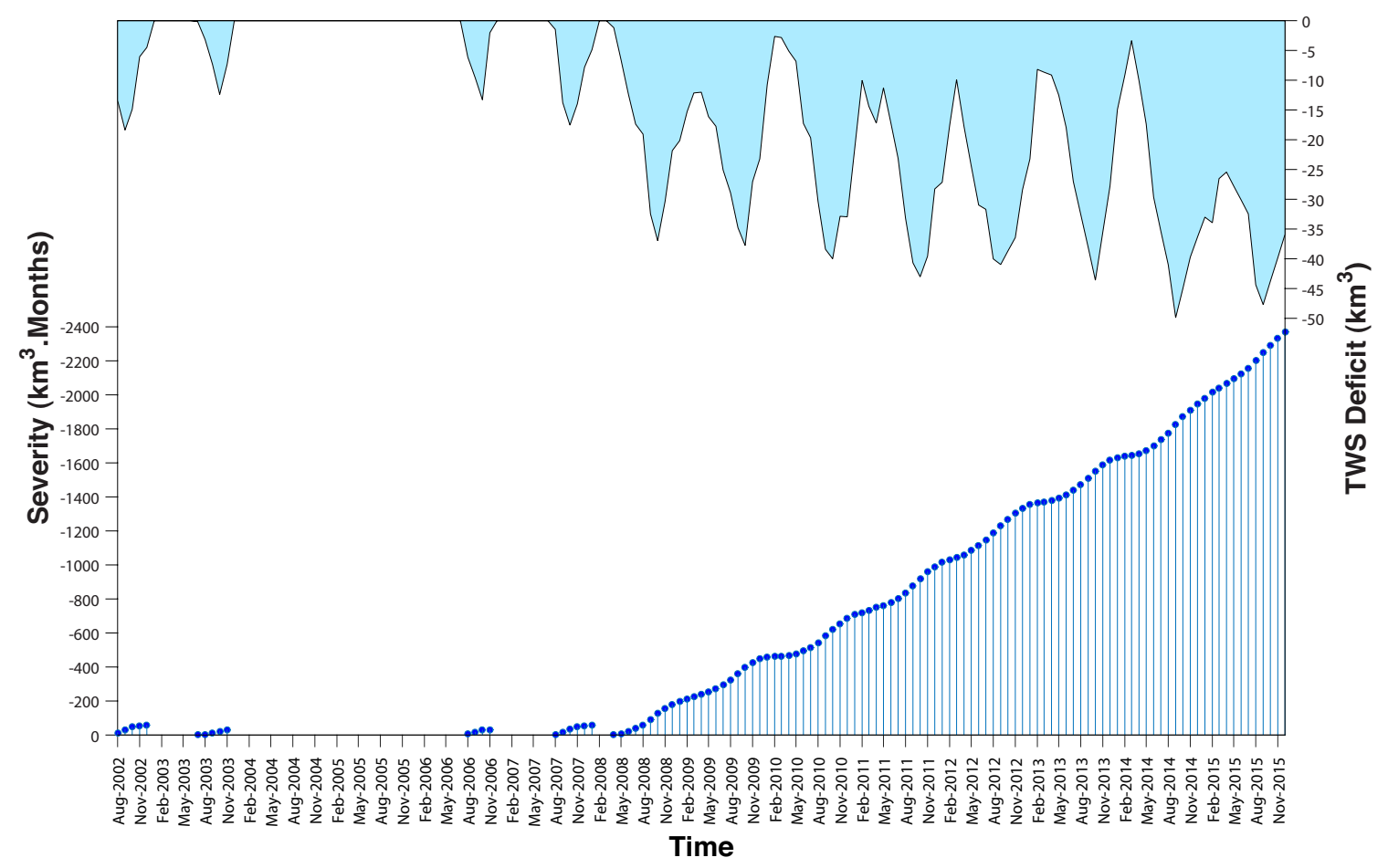

Figure 16: Severity for different drought events shown in blue stem diagram, and deficit shown in shaded area.

Normal and minimal time to recover from drought for each time step is shown in Figure 17a. The longest time to recover is recorded in September 2014 as 14 months and 4 months for normal and best conditions respectively. This corresponds to the month with highest deficit of $49.9 \mathrm{~km}^{3}$ (see Table 6).

The recovery time as described in section 3.1.2.3 is verified by another approach proposed by Parry et al. (2016). Both methods provided close results in terms of recovery time (see Figure 17 (a) and (b)). However, the mathematical approach in Figure 17b cannot estimate drought recovery time unless one has actually occurred. For instance, the fourth and most severe drought recovery time is not computable based on the latter approach since no recovery (surplus for $\geq 3$ months) has occurred. 

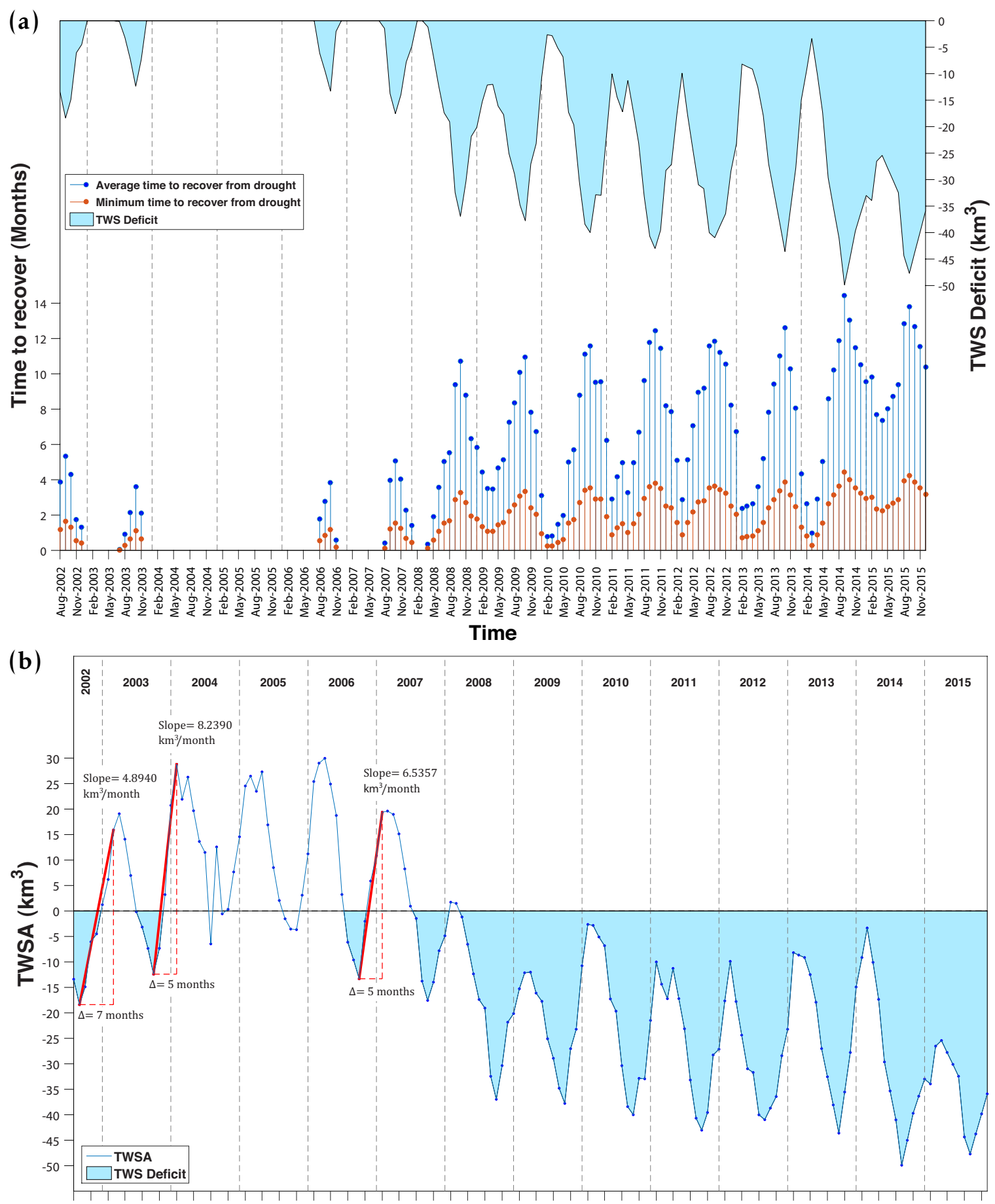

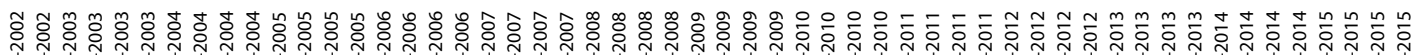

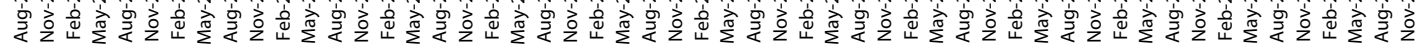

Time

Figure 17: Drought recovery time based on (a) Statistical approach (Thomas et al., 2014). (b) Mathematical approach (Parry et al., 2016). Vertical black dashed lines denotes the end of a calender year. 
In order to classify the last drought event, Nash Sutcliff Efficiency (NSE), Root Mean Square Error (RMSE), and Normalized Mean Bias (NMB) in Equation 11, Equation 12, and Equation 13 respectively; are compared for the four drought severity lines in Figure 14, and the results are shown in Table 7. The severity line $C=-3$ is found to be the closest to CTSD line, so its equation is used to derive $p$ and $q$ values for the calculation of TSDI as described in section 3.1.2.4.

$$
\begin{aligned}
& \text { RMSE }=\sqrt{\frac{1}{n} \sum_{1}^{n}\left(q^{o b s}-q^{s i m}\right)^{2}} \\
& N S E=1-\frac{\sum_{1}^{n}\left(q^{o b s}-q^{s i m}\right)^{2}}{\sum_{1}^{n}\left(q^{o b s}-\overline{q^{o b s}}\right)^{2}} \\
& N M B=\frac{\sum_{1}^{n}\left(q^{s i m}-q^{o b s}\right)}{\sum_{1}^{n} q^{o b s}} \times 100
\end{aligned}
$$

Where $n$ represents the total number of CTSD monthly values from March 2008 till December 2015. $q^{\text {obs }}$ corresponds to the values of CTSD line, and $q^{\text {sim }}$ corresponds to the values of one of the dashed lines in Figure 14. 
Table 7: Comparison of drought severity lines with CTSD line.

\begin{tabular}{llll}
\hline$C$ & RMSE & NMB & NSE \\
\hline-1 & 868.36 & -68.07 & -0.45 \\
-2 & 515.46 & -36.39 & 0.48 \\
-3 & 204.77 & -4.71 & $\mathbf{0 . 9 1}$ \\
-4 & 287.66 & 26.96 & 0.84 \\
\hline
\end{tabular}

A clear deterioration in drought condition is noticed in the region from 2008 until 2015, where the drought severity class gradually shifted from normal to extreme condition as shown in Figure 18. Although the fourth drought event started in August 2007 (see Table 6), the TSDI is calculated starting from March 2008, because TSDI calculation methodology requires a continuous drought event where no surplus occurrence in between. In this case, there are two months of surplus in February and March 2008, therefore March 2008 is chosen as a starting point for TSDI calculation.

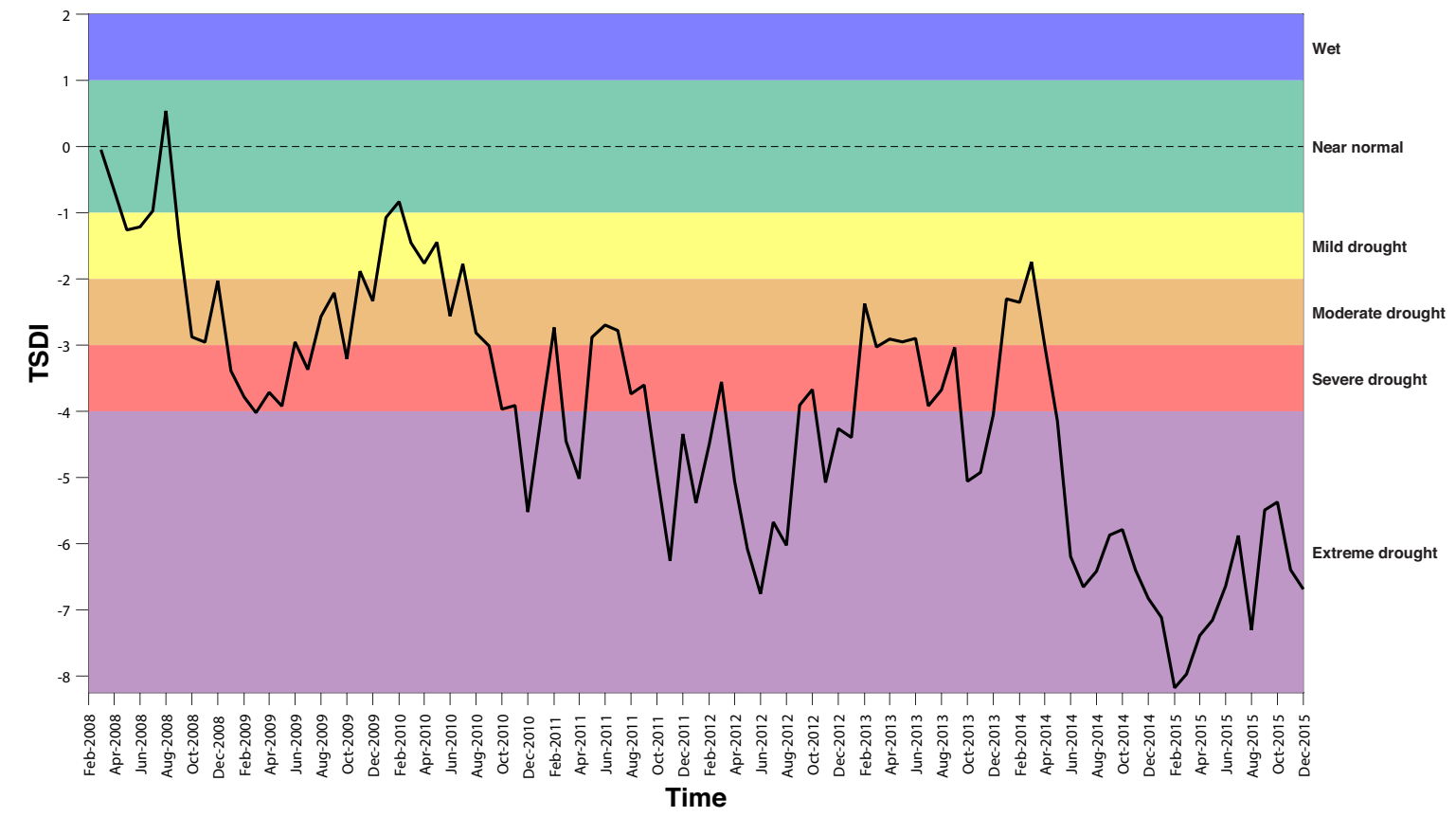

Figure 18: Classification of drought severity using total storage deficit index over Iraq for the fourth observed drought event. 
An investigation is carried out about the possible causes of hydrological drought in the last decade. One might expect hydrological drought to occur as a result of a preceding meteorological drought since it's the nature of the drought event propagation (Van Loon, 2015), but the results depicted in Figure 19 show a clear decline in TWSA, while precipitation does not show similar pattern even if lag time is considered. The same can be inferred about temperature since no significant increment in temperature trend can be noticed. These findings are verified by testing temperature, precipitation, and TWSA trends using Mann-Kendall test as described in section 3.1.2.5. The test is performed at significance level of 0.05 and the results indicate a significant decreasing trend for TWSA, and no significant trend for precipitation and temperature.

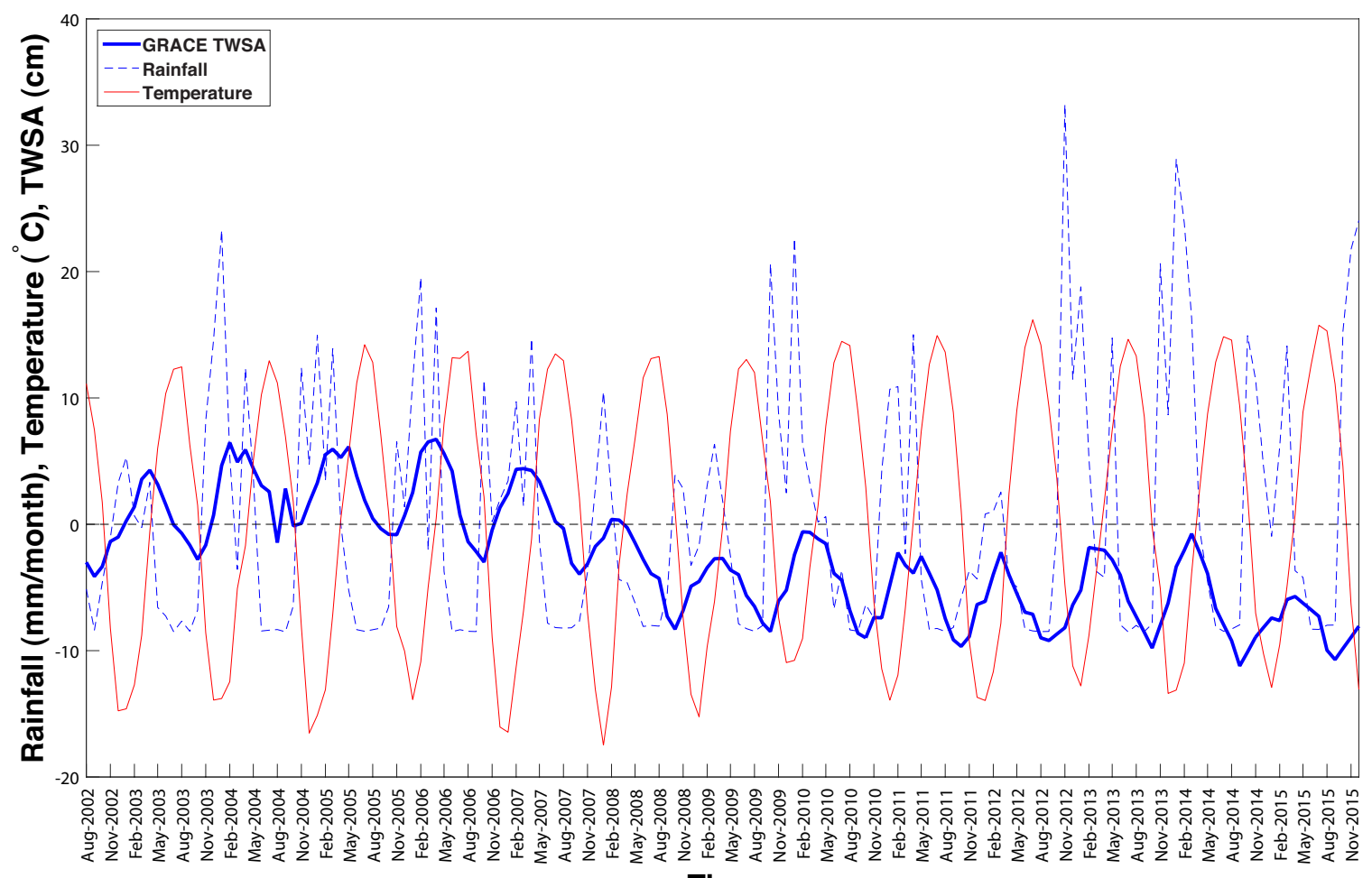

Time

Figure 19: Time series for TWSA, Precipitation, and Temperature as deviation from mean, where mean temperature is $23.65^{\circ} \mathrm{C}$, and mean precipitation is 8.5 $\mathrm{mm} / \mathrm{month}$. 
Because of the aforementioned results inferred from atmospheric factors, it is plausible to assume that hydrological drought in the last decade is more related to surface/subsurface water shortage. This assumption coincides with the results reported in Mulder et al. (2015), and Voss et al. (2013), where a clear surface water declination was observed. Although the data analysis in these studies did not extend up to 2015, it is possible that this decline has continued up to the end of 2015. As such, UNESCO (2014) report predicted a significant decline in water levels in the coming years due to futuristic upstream irrigation projects and predicted precipitation decline. Also, Chulov (2009) reported that in fall 2009 Euphrates had a flow within Iraqi territories about 70\% below normal flow.

Shortage in surface water leads by nature to the dependency on ground water, which in turn exacerbate the water deficiency issue to deeper layers into the ground that is not easily replenished (Voss et al., 2013). For instance, Qadisiyah reservoir, one of the major reservoirs on Euphrates, experienced a sharp drop in water levels in 2007, and that was mainly attributed to the reduction of groundwater (UNESCO, 2014; Voss et al., 2013). According to Chulov (2009), about 1000 groundwater wells were dug between 2007 and 2009 by the Iraqi government in order to take advantage of the high water table available during those drought years. Without replenishment from the surface, the consequence was the depletion of ground water storage in 2009 to about $20 \%$ of the 2007's storage (Chulov, 2009). 


\section{Chapter Four: Conclusion}

Remote sensing has been utilized in a mission to monitor agricultural drought over Iraq, a data-inaccessible region where this phenomenon has not been addressed and studied on a nationwide scale yet. Four indices were employed in order to understand the spatio-temporal distribution of agricultural drought in Iraq. In addition to geographic distribution of drought, a classification scheme was also provided in order to understand the most affected areas. Only VSDI and VDI were proved to be applicable over the study area. Since VSDI does not incorporate temperature in its calculation, an important factor that affects drought, VDI was found to be more suitable for Iraq because of temperature integration in its structure in addition to meeting the assumptions it was based on.

Geographically, VDI drought maps have shown that the far northeastern part of Iraq is the least to experience drought among the vegetated areas of the country. 2008 was found to be the most severe year during the study period dominated by around $37 \%$ of severe drought, while 2009, 2011, and 2012 were the less-severe drought years dominated by mild or moderate drought with an areal coverage of $44 \%, 50 \%$, and $48.5 \%$ respectively. These results have been compared with the findings of other studies and found to be rational. This study is conducted to fulfill the need of a nationwide scale and updated to the recent years, agricultural drought monitoring system that can be utilized as an early warning system.

In terms of hydrological drought, we used GRACE satellite product that measures the change in surface and subsurface water amount in land. This holistic measure provided the ground base for a comprehensive understanding of hydrological drought over Iraq in the recent years, which as a phenomenon has not been investigated adequately in literature over this region. The study results covered a

quantitative sense of drought represented by estimates of deficit, severity, and recov- 
ery on monthly basis. Classification of drought severity was also introduced in this study as a tool for decision-making. Similar to agricultural drought, remote sensing data was utilized to characterize hydrological drought over a data-scarce region. The results were verified on different classes, and showed agreement with other studies with the advantage of extending the analysis up to recent time. Iraq has suffered from several hydrological droughts since 2003. The droughts were minor in terms of duration and magnitude except the last one, which showed persistence and high deficit from August 2007 until December 2015. It is worth mentioning that the new Ilisu dam located in the Turkish part of Tigris river upstream is expected to enter the filling stage in 2017, since it has reached the final phase of construction by the end of 2016 (Conker, 2016; Hommes et al., 2016). Due to this forthcoming change in the hydrologic system of Tigris river, it is expected that Tigris flow would be decreased by around 50\% when Ilisu dam is in operation (Al-Ansari et al., 2014; Al-Muqdadi et al., 2016), which will greatly exacerbate hydrological drought in Iraq. The procedure in this study can be used to provide evidence of water shortage and hydrological drought occurrence in any region, which can be a handful tool for negotiations regarding water rights between riparian countries. 


\section{REFERENCES}

A, G., Velicogna, I., Kimball, J. S., \& Kim, Y. (2015). Impact of changes in GRACE derived terrestrial water storage on vegetation growth in Eurasia. Environmental Research Letters, 10(12), 124024. Retrieved from http://doi .org/10.1088/ 1748-9326/10/12/124024 doi: 10.1088/1748-9326/10/12/124024

Abd-El-Mooty, M., Kansoh, R., \& Abdulhadi, A. (2016). Challenges of Water Resources in Iraq. Hydrology Current Research, 7(4). Retrieved from http: // doi.org/10.4172/2157-7587.1000260 doi: 10.4172/2157-7587.1000260

Ahmad, I., Al-Hamadani, N., \& Ibrahim, K. (1983). Solar radiation maps for Iraq. Solar Energy, 31(1), 29-44. Retrieved from http:// doi .org/10.1016/ 0038-092X(83)90031-2 doi: 10.1016/0038-092X(83)90031-2

Ahmadalipour, A., Moradkhani, H., \& Svoboda, M. (2017a). Centennial drought outlook over the CONUS using NASA-NEX downscaled climate ensemble. International Journal of Climatology, 37(5), 2477-2491. Retrieved from ht tp: / / doi.org/10.1002/joc.4859 doi: 10.1002/joc.4859

Ahmadalipour, A., Moradkhani, H., Yan, H., \& Zarekarizi, M. (2017b). Remote Sensing of Drought: Vegetation, Soil Moisture, and Data Assimilation. In V. Lakshmi (Ed.), Remote sensing of hydrological extremes (pp. 121-149). Cham: Springer International Publishing. Retrieved from http://doi .org/ 10. 1007/978-3-319-43744-6_7 doi: 10.1007/978-3-319-43744-6_7

Al-Ansari, N., Ali, A. A., \& Knutsson, S. (2014). Present Conditions and Future Challenges of Water Resources Problems in Iraq. Journal of Water Resource and Protection, 06(12), 1066-1098. Retrieved from http://doi.org/10.4236/ jwarp.2014.612102 doi: 10.4236/jwarp.2014.612102 
Al-Muqdadi, S. W., Omer, M. F., Abo, R., \& Naghshineh, A. (2016). Dispute over Water Resource ManagementIraq and Turkey. Journal of Environmental Protection, 07(08), 1096-1103. Retrieved from http://doi.org/10.4236/ jep.2016.78098 doi: 10.4236/jep.2016.78098

AL-Timimi, Y., \& AL-Jiboori, M. (2013). Assessment of spatial and temporal drought in Iraq during the period 1980-2010. International Journal of Energy and Environment, 4(2), 291-302. Retrieved from http: //www. i jee. ieefoundation .org/vol4/issue2/IJEE_12_v4n2.pdf

Anyamba, A., \& Tucker, C. (2012). Historical Perspectives on AVHRR NDVI and Vegetation Drought Monitoring. In Remote sensing of drought (pp. 2350). CRC Press. Retrieved from http://www.crcnetbase.com/doi/abs/ 10.1201/b11863-4 doi: doi:10.1201/b11863-4

Awange, J., Khandu, Schumacher, M., Forootan, E., \& Heck, B. (2016). Exploring hydro-meteorological drought patterns over the Greater Horn of Africa (19792014) using remote sensing and reanalysis products. Advances in Water Resources, 94, 45-59. Retrieved from http://doi.org/10.1016/ j.advwatres.2016.04.005 doi: 10.1016/j.advwatres.2016.04.005

Bettadpur, S. (2012). GRACE level-2 gravity field product user handbook. GRACE 327-734 (CSR-GR-03-01). Center for Space Research, The University of Texas at Austin. Retrieved from http://podaac-w10n. jpl.nasa.gov/w10n/ allData/grace/retired/L2/CSR/RL00/docs/L2-UserHandbook_v3.0.pdf

Brown, L., \& Mac Berthouex, P. (2002). Statistics for Environmental Engineers, Second Edition. CRC Press. Retrieved from http://doi.org/10.1201/ 9781420056631 doi: $10.1201 / 9781420056631$ 
Cao, Feng, Y., Wang, J., Gao, Z., Ning, J., \& Gao, W. (2014). The study of the spatiotemporal changes of drought in the Mongolian Plateau in 40 years based on TVDI. In W. Gao, N.-B. Chang, \& J. Wang (Eds.), (p. 92210X). Retrieved from http://doi.org/10.1117/12.2059062 doi: 10.1117/12.2059062

Cao, Nan, Z., \& Cheng, G. (2015). GRACE Gravity Satellite Observations of Terrestrial Water Storage Changes for Drought Characterization in the Arid Land of Northwestern China. Remote Sensing, 7(1), 1021-1047. Retrieved from http://doi.org/10.3390/rs70101021 doi: 10.3390/rs70101021

Chambers, D. P., \& Bonin, J. A. (2012). Evaluation of Release-05 GRACE timevariable gravity coefficients over the ocean. Ocean Science, 8(5), 859-868. Retrieved from http://doi.org/10.5194/os-8-859-2012 doi: 10.5194/ os-8-859-2012

Cheng, Hoerling, M., AghaKouchak, A., Livneh, B., Quan, X.-W., \& Eischeid, J. (2016). How Has Human-Induced Climate Change Affected California Drought Risk? Journal of Climate, 29(1), 111-120. Retrieved from http:// doi .org/10.1175/ JCLI-D-15-0260. 1 doi: 10.1175/JCLI-D-15-0260.1

Cheng, \& Tapley, B. D. (2004). Variations in the Earth's oblateness during the past 28 years. Journal of Geophysical Research B: Solid Earth, 109(9), n/an/a. Retrieved from http://doi.org/10.1029/2004JB003028 doi: 10.1029/ 2004JB003028

Chulov, M. (2009). Iraq: Water, Water Nowhere. World Policy Journal, 26(4), 33-41. Retrieved from http://wp j.duke journals.org/content/26/4/33 .citation doi: 10.1162/wopj.2010.26.4.33 
Conker, A. (2016). THE POWER STRUGGLE IN THE LAYER OF TRANSNATIONAL HYDROPOLITICS: THE CASE OF THE ILISU DAM PROJECT. Eurasian Journal of Social Sciences, 4(4), 14-34. Retrieved from http: // do i .org/10.15604/ejss.2016.04.04.002 doi: 10.15604/ejss.2016.04.04.002

Dai, A., \& Zhao, T. (2016). Uncertainties in historical changes and future projections of drought. Part I: estimates of historical drought changes. Climatic Change. Retrieved from http://doi.org/10.1007/s10584-016-1705-2 doi: $10.1007 / \mathrm{s} 10584-016-1705-2$

De Martonne, E. (1926). Géographie physique. Aréisme et indice d'aridité. GauthierVillars.

DeChant, C., \& Moradkhani, H. (2014). Examining the Reliability of Hydrologic Drought-Risk Forecasting at Seasonal Timescales. In World environmental and water resources congress 2014 (pp. 2336-2346). Reston, VA: American Society of Civil Engineers. Retrieved from http://doi .org/10 . 1061/9780784413548 .233 doi: $10.1061 / 9780784413548.233$

DeChant, C., \& Moradkhani, H. (2015). Analyzing the sensitivity of drought recovery forecasts to land surface initial conditions. Journal of Hydrology, 526, 89-100. Retrieved from http://doi.org/10.1016/ j . jhydrol.2014.10.021 doi: 10.1016/j.jhydrol.2014.10.021

Dhorde, A., \& Patel, N. (2016). Spatio-temporal variation in terminal drought over western India using dryness index derived from long-term MODIS data. Ecological Informatics, 32, 28-38. Retrieved from http://doi .org/10.1016/ j.ecoinf.2015.12.007 doi: 10.1016/j.ecoinf.2015.12.007

Didan, K. (2015). MOD13C2 MODIS/Terra Vegetation Indices Monthly L3 Global 0.05Deg CMG V006. Retrieved from http://doi.org/10.5067/MODIS/ MOD13C2.006 doi: 10.5067/MODIS/MOD13C2.006 
Eklund, L., \& Seaquist, J. (2015). Meteorological, agricultural and socioeconomic drought in the Duhok Governorate, Iraqi Kurdistan. Natural Hazards, 76(1), 421-441. Retrieved from http://doi.org/10.1007/s11069-014-1504-x doi: $10.1007 / \mathrm{s} 11069-014-1504-\mathrm{x}$

European Commission. (2006). Water Scarcity and Drought, First Interim Report (Tech. Rep.). Retrieved from http://ec.europa.eu/environment/water/ pdf/1st_report.pdf

Famiglietti, J. S., Lo, M., Ho, S. L., Bethune, J., Anderson, K. J., Syed, T. H., Swenson, S. C., de Linage, C. R., \& Rodell, M. (2011). Satellites measure recent rates of groundwater depletion in California's Central Valley. Geophysical Research Letters, 38(3), n/a-n/a. Retrieved from http://doi .org/10.1029/ 2010GL046442 doi: 10.1029/2010GL046442

FAO, \& World Bank. (2011). Iraq Agriculture sector note (Tech. Rep.). Retrieved from http://www.fao.org/docrep/017/i2877e/i2877e.pdf

Fleig, A. K., Tallaksen, L. M., Hisdal, H., \& Hannah, D. M. (2011). Regional hydrological drought in north-western Europe: linking a new Regional Drought Area Index with weather types. Hydrological Processes, 25(7), 1163-1179. Retrieved from http://doi.org/10.1002/hyp.7644 doi: 10.1002/hyp.7644

Gao, B. C. (1996). NDWI - A normalized difference water index for remote sensing of vegetation liquid water from space. Remote Sensing of Environment, 58(3), 257-266. Retrieved from http:// doi .org/10 . 1016/S0034-4257 (96) 00067 -3 doi: 10.1016/S0034-4257(96)00067-3 
Garcia, M., Fernández, N., Villagarcía, L., Domingo, F., Puigdefábregas, J., \& Sandholt, I. (2014). Accuracy of the TemperatureVegetation Dryness Index using MODIS under water-limited vs. energy-limited evapotranspiration conditions. Remote Sensing of Environment, 149, 100-117. Retrieved from http: // doi.org/10.1016/j.rse.2014.04.002 doi: 10.1016/j.rse.2014.04.002

Gebrehiwot, T., Van der Veen, A., \& Maathuis, B. (2016). Governing agricultural drought: Monitoring using the vegetation condition index. Ethiopian Journal of Environmental Studies and Management, 9(3), 354. Retrieved from http: / / doi.org/10.4314/e jesm.v9i3.9 doi: 10.4314/ejesm.v9i3.9

Ghaleb, F., Mario, M., \& Sandra, A. (2015). Regional Landsat-Based Drought Monitoring from 1982 to 2014. Climate, 3(3), 563-577. Retrieved from http://doi.org/10.3390/cli3030563 doi: 10.3390/cli3030563

Gu, Y., Brown, J. F., Verdin, J. P., \& Wardlow, B. (2007). A five-year analysis of MODIS NDVI and NDWI for grassland drought assessment over the central Great Plains of the United States. Geophysical Research Letters, 34(6), L06407. Retrieved from http://doi.org/10.1029/2006GL029127 doi: 10.1029/2006GL029127

Guijarro, J. (2014). Quality Control and Homogenization of Climatological Series. In Handbook of engineering hydrology (pp. 501-513). CRC Press. Retrieved from http://doi.org/doi:10.1201/b15625-25 doi: doi:10.1201/b15625-25

Gunda, T., Hornberger, G. M., \& Gilligan, J. M. (2016). Spatiotemporal Patterns of Agricultural Drought in Sri Lanka: 1881-2010. International Journal of Climatology, 36(2), 563-575. Retrieved from http://doi .org/10.1002/ joc .4365 doi: 10.1002/joc.4365 
Guo, J., Mu, D., Liu, X., Yan, H., Sun, Z., \& Guo, B. (2016). Water Storage Changes over the Tibetan Plateau Revealed by GRACE Mission. Acta Geophysica, 64(2), 463-476. Retrieved from http://doi.org/10.1515/acgeo-2016-0003 doi: 10.1515/acgeo-2016-0003

Gustard, A., Blazkova, S., Brilly, M., Demuth, S., Dixon, J., Van Lanen, H., Llasat, C., Mkhandi, S., \& Servat, E. (1997). FRIEND'97: Regional Hydrology: Concepts and Models for Sustainable Water Resource Management (No. 246). International Association of Hydrological Sciences.

Hamed, K. H., \& Ramachandra Rao, A. (1998). A modified Mann-Kendall trend test for autocorrelated data. Journal of Hydrology, 204(1-4), 182-196. Retrieved from http://doi.org/10.1016/S0022-1694(97)00125-X doi: 10.1016/S0022-1694(97)00125-X

Hassan, A., Kareem, A., \& Laftah, A. (2012). Integration Study of Vegetation Cover in Babil Governorate By Using Remote Sensing Data and GIS. Journal of Babylon University, 22(1), 564-579. Retrieved from http: //www. ias j . net/ ias $\mathrm{j}$ ? func $=$ full text\&aId=81783

Holzman, M., Rivas, R., \& Piccolo, M. (2014). Estimating soil moisture and the relationship with crop yield using surface temperature and vegetation index. International Journal of Applied Earth Observation and Geoinformation, 28, 181192. Retrieved from http://doi.org/10.1016/j.jag.2013.12.006 doi: 10.1016/j.jag.2013.12.006

Hommes, L., Boelens, R., \& Maat, H. (2016). Contested hydrosocial territories and disputed water governance: Struggles and competing claims over the Ilisu Dam development in southeastern Turkey. Geoforum, 71, 9-20. Retrieved from http://doi.org/10.1016/j.geoforum.2016.02.015 doi: 10.1016/ j.geoforum.2016.02.015 
Hosseinzadeh Talaee, P., Tabari, H., \& Sobhan Ardakani, S. (2014). Hydrological drought in the west of Iran and possible association with large-scale atmospheric circulation patterns. Hydrological Processes, 28(3), 764-773. Retrieved from http://doi.org/10.1002/hyp.9586 doi: 10.1002/hyp.9586

Hussein, M. H., Amien, I. M., \& Kariem, T. H. (2016). Designing terraces for the rainfed farming region in Iraq using the RUSLE and hydraulic principles. International Soil and Water Conservation Research, 4(1), 3944. Retrieved from http://doi.org/10.1016/j.iswcr.2015.12.002 doi: 10.1016/j.iswcr.2015.12.002

Jassim, S. Z., \& Goff, J. C. (2006). Geology of Iraq. DOLIN, sro, distributed by Geological Society of London.

Karnieli, A., Agam, N., Pinker, R. T., Anderson, M., Imhoff, M. L., Gutman, G. G., Panov, N., \& Goldberg, A. (2010). Use of NDVI and Land Surface Temperature for Drought Assessment: Merits and Limitations. Journal of Climate, 23(3), 618-633. Retrieved from http://doi.org/10.1175/2009JCLI2900.1 doi: 10.1175/2009JCLI2900.1

Kimura, R. (2007). Estimation of moisture availability over the Liudaogou river basin of the Loess Plateau using new indices with surface temperature. Journal of Arid Environments, 70(2), 237-252. Retrieved from http://doi .org/10 .1016/ j . jaridenv. 2006.12.021 doi: 10.1016/j.jaridenv.2006.12.021

Klees, R., Revtova, E. A., Gunter, B. C., Ditmar, P., Oudman, E., Winsemius, H. C., \& Savenije, H. H. G. (2008). The design of an optimal filter for monthly GRACE gravity models. Geophysical Journal International, 175(2), 417-432. Retrieved from http:// doi.org/10.1111/ j.1365-246X.2008.03922.x doi: 10.1111/j.1365-246X.2008.03922.x 
Kogan, F. (1995). Application of vegetation index and brightness temperature for drought detection. Advances in Space Research, 15(11), 91-100. Retrieved from http://doi .org/10.1016/0273-1177(95)00079-T doi: 10.1016/0273 -1177(95)00079-T

Kogan, F. (2001). Operational Space Technology for Global Vegetation Assessment. Bulletin of the American Meteorological Society, 82(9), 1949-1964. Retrieved from http://doi .org/10 .1175/1520-0477(2001)082\%3C1949:0STFGV\%3E2 .3.C0;2 doi: 10.1175/1520-0477(2001)082〈1949:OSTFGV〉2.3.CO;2

Langbein, L. (2006). Public Program Evaluation. Routledge. Retrieved from http://doi.org/10.4324/9781315497891 doi: 10.4324/9781315497891

Lloyd-Hughes, B. (2014). The impracticality of a universal drought definition. Theoretical and Applied Climatology, 117(3-4), 607-611. Retrieved from http:// doi .org/10 . 1007/s00704-013-1025-7 doi: 10.1007/s00704-013-1025-7

Madadgar, S., \& Moradkhani, H. (2013a). A Bayesian Framework for Probabilistic Seasonal Drought Forecasting. Journal of Hydrometeorology, 14(6), 1685-1705. Retrieved from http://doi.org/10.1175/JHM-D-13-010.1 doi: 10.1175/ JHM-D-13-010.1

Madadgar, S., \& Moradkhani, H. (2013b). Drought Analysis under Climate Change Using Copula. Journal of Hydrologic Engineering, 18(7), 746-759. Retrieved from http:// doi.org/10.1061/( ASCE)HE. 1943-5584.0000532 doi: 10.1061/(ASCE)HE.1943-5584.0000532

Madadgar, S., \& Moradkhani, H. (2014). Spatio-temporal drought forecasting within Bayesian networks. Journal of Hydrology, 512, 134-146. Retrieved from http://doi.org/10.1016/j . jhydrol.2014.02.039 doi: 10.1016/j.jhydrol .2014 .02 .039 
Marti, U. (2014). Gravity, geoid and height systems (Vol. 141; U. Marti, Ed.). Cham: Springer International Publishing. Retrieved from http://doi .org/ 10. 1007/978-3-319-10837-7 doi: 10.1007/978-3-319-10837-7

Medellín-Azuara, J., MacEwan, D., Howitt, R. E., Sumner, D. A., \& Lund, J. R. (2016). Economic Analysis of the 2016 California Drought on Agriculture (Tech. Rep.). Davis, California: California Department of Food and Agriculture. Retrieved from https://watershed.ucdavis.edu/files/ DroughtReport_20160812.pdf

Meyrath, T., \& van Dam, T. (2016). A comparison of interannual hydrological polar motion excitation from GRACE and geodetic observations. Journal of Geodynamics, 99, 1-9. Retrieved from http://doi.org/10.1016/ j.jog .2016.03.011 doi: 10.1016/j.jog.2016.03.011

Mishra, A. K., \& Singh, V. P. (2010). A review of drought concepts. Journal of Hydrology, 391(1-2), 202-216. Retrieved from http://doi.org/10.1016/ j.jhydrol.2010.07.012 doi: 10.1016/j.jhydrol.2010.07.012

Muhaimeed, A., \& M, A.-H. (2013). Evaluation of long-term vegetation trends for northeastern of Iraq: Mosul, Kirkuk and Salah al-Din. IOSR Journal of Agriculture and Veterinary Science, 5(2), 67-76. Retrieved from http : / / iosr journals . org/iosr-javs/papers/vol5-issue2/K0526776 . pdf?id=8064

Mulder, G., Olsthoorn, T. N., Al-Manmi, D. A. M. A., Schrama, E. J. O., \& Smidt, E. H. (2015). Identifying water mass depletion in northern Iraq observed by GRACE. Hydrology and Earth System Sciences, 19(3), 1487-1500. Retrieved from http://doi.org/10.5194/hess-19-1487-2015 doi: 10.5194/hess-19 $-1487-2015$

Nalbantis, I. (2008). Evaluation of a Hydrological Drought Index. European Water, $2324,67-77$. 
NASA JPL. (2009). ASTER Global Digital Elevation Model [Data set] NASA JPL. Retrieved from http://doi.org/10.5067/ASTER/ASTGTM. 002 doi: 10.5067/ ASTER/ASTGTM.002

NASA/GSFC. (2002). Studying the Earth's Gravity from Space: The Gravity Recovery and Climate Experiment (GRACE)[Fact sheet] (Tech. Rep.). Retrieved from http://www.csr.utexas.edu/grace/publications/fact _sheet/GRACE_Fact_Sheet.pdf

NOAA. (2008). Drought[Fact sheet] (Tech. Rep.). Retrieved from http: / /www. nws .noaa.gov/os/brochures/climate/DroughtPublic2.pdf

NOAA. (2012). Drought[Fact sheet]. Retrieved from http://www. nws . noaa.gov/ om/csd/graphics/content/outreach/brochures/FactSheet_Drought .$p d f$

Omer, T. (2011). Country Pasture/Forage Resource Profile, Iraq. Retrieved 2016-01-01, from http://www.fao.org/ag/agp/agpc/doc/counprof/iraq/i raq.html

Ouyang, W., Liu, B., \& Wu, Y. (2016). Satellite-based estimation of watershed groundwater storage dynamics in a freezethaw area under intensive agricultural development. Journal of Hydrology, 537, 96-105. Retrieved from http://doi.org/10.1016/j.jhydrol.2016.03.034 doi: 10.1016/ j.jhydrol.2016.03.034

Owrangi, M. A. (2011). Drought Monitoring Methodology Based on AVHRR Images and SPOT Vegetation Maps. Journal of Water Resource and Protection, 03(05), 325-334. Retrieved from http:// doi . org/ 10.4236/ jwarp.2011.35041 doi: 10.4236/jwarp.2011.35041

Palmer, W. C. (1965). Meteorological drought (Vol. 30). US Department of Commerce, Weather Bureau Washington, DC. Retrieved from https: //www.ncdc. noaa .gov/temp-and-precip/drought/docs/palmer .pdf 
Parry, S., Wilby, R. L., Prudhomme, C., \& Wood, P. J. (2016). A systematic assessment of drought termination in the United Kingdom. Hydrology and Earth System Sciences Discussions(January), 1-33. Retrieved from http: // doi.org/10.5194/hess-2015-476 doi: 10.5194/hess-2015-476

Rahimzadeh-Bajgiran, P., Omasa, K., \& Shimizu, Y. (2012). Comparative evaluation of the Vegetation Dryness Index (VDI), the Temperature Vegetation Dryness Index (TVDI) and the improved TVDI (iTVDI) for water stress detection in semi-arid regions of Iran. ISPRS Journal of Photogrammetry and Remote Sensing, 68, 1-12. Retrieved from http://doi.org/10.1016/ j . isprs jprs.2011. 10 009 doi: 10.1016/j.isprsjprs.2011.10.009

Rana, A., \& Moradkhani, H. (2016). Spatial, temporal and frequency based climate change assessment in Columbia River Basin using multi downscaled-scenarios. Climate Dynamics, 47(1-2), 579-600. Retrieved from http://doi.org/10 . 1007/s00382-015-2857-x doi: 10.1007/s00382-015-2857-x

Rana, A., Moradkhani, H., \& Qin, Y. (2016). Understanding the joint behavior of temperature and precipitation for climate change impact studies. Theoretical and Applied Climatology. Retrieved from http: / / doi .org/10 . 1007/s00704 -016-1774-1 doi: 10.1007/s00704-016-1774-1

Rembold, F., Meroni, M., Rojas, O., Atzberger, C., Ham, F., \& Fillol, E. (2015). Agricultural Drought Monitoring Using Space-Derived Vegetation and Biophysical Products: A Global Perspective. In Remote sensing of water resources, disasters, and urban studies (pp. 349-365). CRC Press.

Rhee, J., Im, J., \& Carbone, G. J. (2010). Monitoring agricultural drought for arid and humid regions using multi-sensor remote sensing data. Remote Sensing of Environment, 114(12), 2875-2887. Retrieved from http : / / doi .org/10 . 1016/ j.rse.2010.07.005 doi: 10.1016/j.rse.2010.07.005 
Rodell, M. (2004). Basin scale estimates of evapotranspiration using GRACE and other observations. Geophysical Research Letters, 31(20), L20504. Retrieved from http://doi.org/10.1029/2004GL020873 doi: 10.1029/ 2004GL020873

Rodell, M., Beaudoing, H. K., \& NASA/GSFC/HSL. (2007). GLDAS Noah Land Surface Model L4 Monthly 0.25 x 0.25 degree , version 001. Greenbelt, Maryland, USA. Retrieved from http://doi.org/10.5067/7NP2052IA62C doi: 10 $.5067 / 7 N P 2052 I A 62 C$

Rodell, M., \& Famiglietti, J. (2002). The potential for satellite-based monitoring of groundwater storage changes using GRACE: the High Plains aquifer, Central US. Journal of Hydrology, 263(1-4), 245-256. Retrieved from http: // doi .org/ 10.1016/S0022-1694(02)00060-4 doi: 10.1016/S0022-1694(02)00060-4

Rojas, O., Vrieling, A., \& Rembold, F. (2011). Assessing drought probability for agricultural areas in Africa with coarse resolution remote sensing imagery. Remote Sensing of Environment, 115(2), 343-352. Retrieved from http:// doi.org/10.1016/ j.rse.2010.09.006 doi: 10.1016/j.rse.2010.09.006

Roudier, P., Andersson, J. C. M., Donnelly, C., Feyen, L., Greuell, W., \& Ludwig, F. (2016). Projections of future floods and hydrological droughts in Europe under a $+2 \mathrm{C}$ global warming. Climatic Change, 135(2), 341-355. Retrieved from http://doi.org/10.1007/s10584-015-1570-4 doi: 10.1007/s10584 $-015-1570-4$

Salami, H., Shahnooshi, N., \& Thomson, K. J. (2009). The economic impacts of drought on the economy of Iran: An integration of linear programming and macroeconometric modelling approaches. Ecological Economics, 68(4), 10321039. Retrieved from http://doi.org/10.1016/j . ecolecon.2008.12.003 doi: 10.1016/j.ecolecon.2008.12.003 
Sandholt, I., Rasmussen, K., \& Andersen, J. (2002). A simple interpretation of the surface temperature/vegetation index space for assessment of surface moisture status. Remote Sensing of Environment, 79(2-3), 213-224. Retrieved from http://doi.org/10.1016/S0034-4257(01)00274-7 doi: 10.1016/S0034-4257(01)00274-7

Schlaepfer, D. R., Bradford, J. B., Lauenroth, W. K., Munson, S. M., Tietjen, B., Hall, S. A., Wilson, S. D., Duniway, M. C., Jia, G., Pyke, D. A., Lkhagva, A., \& Jamiyansharav, K. (2017). Climate change reduces extent of temperate drylands and intensifies drought in deep soils. Nature Communications, 8 , 14196. Retrieved from http://doi.org/10.1038/ncomms14196 doi: 10 $.1038 /$ ncomms 14196

Schnepf, R. (2003). Iraq's Agriculture: Background and Status (Tech. Rep.). Congress. Retrieved from http://nationalaglawcenter.org/wp-content/uploads/ assets/crs/RS21516.pdf

Sheffield, J., \& Wood, E. F. (2011). Drought: Past Problems and Future Scenarios. Routledge, London.

Sholihah, R. I., Trisasongko, B. H., Shiddiq, D., Iman, L. O. S., Kusdaryanto, S., Manijo, \& Panuju, D. R. (2016). Identification of Agricultural Drought Extent Based on Vegetation Health Indices of Landsat Data: Case of Subang and Karawang, Indonesia. Procedia Environmental Sciences, 33, 1420. Retrieved from http://doi.org/10.1016/ j . proenv.2016.03.051 doi: 10.1016/j.proenv.2016.03.051 
Singh, R. P., Roy, S., \& Kogan, F. (2003). Vegetation and temperature condition indices from NOAA AVHRR data for drought monitoring over India. International Journal of Remote Sensing, 24(22), 4393-4402. Retrieved from http://doi.org/10.1080/0143116031000084323 doi: 10 $.1080 / 0143116031000084323$

Son, N., Chen, C., Chen, C., Chang, L., \& Minh, V. (2012). Monitoring agricultural drought in the Lower Mekong Basin using MODIS NDVI and land surface temperature data. International Journal of Applied Earth Observation and Geoinformation, 18, 417-427. Retrieved from http://doi .org/10.1016/ j. jag.2012.03.014 doi: 10.1016/j.jag.2012.03.014

Srivastava, P., Petropoulos, G., \& Kerr, Y. (2016). Satellite Soil Moisture Retrieval (1st ed.).

Sruthi, S., \& Aslam, M. M. (2015). Agricultural Drought Analysis Using the NDVI and Land Surface Temperature Data; a Case Study of Raichur District. Aquatic Procedia, 4, 1258-1264. Retrieved from http://doi.org/10.1016/ j.aqpro.2015.02.164 doi: 10.1016/j.aqpro.2015.02.164

Sun, H., Zhao, X., Chen, Y., Gong, A., \& Yang, J. (2013). A new agricultural drought monitoring index combining MODIS NDWI and daynight land surface temperatures: a case study in China. International Journal of Remote Sensing, 34(24), 8986-9001. Retrieved from http:// doi .org/10 . 1080/ 01431161.2013.860659 doi: 10.1080/01431161.2013.860659

Swenson, S., Chambers, D., \& Wahr, J. (2008). Estimating geocenter variations from a combination of GRACE and ocean model output. Journal of Geophysical Research: Solid Earth, 113(8), B08410. Retrieved from http://doi.org/ 10. 1029/2007JB005338 doi: 10.1029/2007JB005338 
Syed, T. H., Famiglietti, J. S., Chen, J., Rodell, M., Seneviratne, S. I., Viterbo, P., \& Wilson, C. R. (2005). Total basin discharge for the Amazon and Mississippi River basins from GRACE and a land-atmosphere water balance. Geophysical Research Letters, 32(24), L24404. Retrieved from http://doi .org/10.1029/ 2005GL024851 doi: 10.1029/2005GL024851

Tallaksen, L. M., Hisdal, H., \& Lanen, H. A. V. (2009). Spacetime modelling of catchment scale drought characteristics. Journal of Hydrology, 375(3-4), 363-372. Retrieved from http://doi.org/10.1016/j.jhydrol.2009.06.032 doi: 10.1016/j.jhydrol.2009.06.032

Thomas, A. C., Reager, J. T., Famiglietti, J. S., \& Rodell, M. (2014). A GRACE-based water storage deficit approach for hydrological drought characterization. Geophysical Research Letters, 41(5), 1537-1545. Retrieved from http: // doi .org/10.1002/2014GL059323 doi: 10.1002/2014GL059323

Tran, H. T., Campbell, J. B., Tran, T. D., \& Tran, H. T. (2017). Monitoring drought vulnerability using multispectral indices observed from sequential remote sensing (Case Study: Tuy Phong, Binh Thuan, Vietnam). GIScience \& Remote Sensing, 54(2), 167-184. Retrieved from http:// doi .org/10 . 1080/15481603 .2017.1287838 doi: 10.1080/15481603.2017.1287838

Trigo, R. M., Gouveia, C. M., \& Barriopedro, D. (2010). The intense 20072009 drought in the Fertile Crescent: Impacts and associated atmospheric circulation. Agricultural and Forest Meteorology, 150(9), 1245-1257. Retrieved from http://doi.org/10.1016/j.agrformet.2010.05.006 doi: 10.1016/j.agrformet.2010.05.006

UN. (2014). Iraq Human Development Report 2014 (Tech. Rep.). Retrieved from http://www.iq.undp.org/content/dam/iraq/img/Publications/ UNDP-IQ_IraqNHDR2014-English.pdf 
UNESCO. (2014). Integrated drought risk management, DRM: national framework for Iraq, an analysis report (Tech. Rep.). Amman: UNESCO Office Iraq (Jordan). Retrieved from http: / / www. unesco.org/new/fileadmin/MULTIMEDIA/F IELD/ Iraq/pdf/Publications/DRM.pdf

Van Loon, A. F. (2015). Hydrological drought explained. Wiley Interdisciplinary Reviews: Water, 2(4), 359-392. Retrieved from http://doi.org/10.1002/ wat2. 1085 doi: $10.1002 /$ wat2.1085

Van Loon, A. F., Gleeson, T., Clark, J., Van Dijk, A. I. J. M., Stahl, K., Hannaford, J., Di Baldassarre, G., Teuling, A. J., Tallaksen, L. M., Uijlenhoet, R., Hannah, D. M., Sheffield, J., Svoboda, M., Verbeiren, B., Wagener, T., Rangecroft, S., Wanders, N., \& Van Lanen, H. A. J. (2016). Drought in the Anthropocene. Nature Geoscience, 9(2), 89-91. Retrieved from http:// doi .org/10.1038/ngeo2646 doi: $10.1038 /$ ngeo 2646

Vermote, E. (2015). MOD09A1 MODIS/Terra Surface Reflectance 8-Day L3 Global 500m SIN Grid V006. Retrieved from http://doi.org/10.5067/MODIS/ MOD09A1.006 doi: 10.5067/MODIS/MOD09A1.006

Voss, K. A., Famiglietti, J. S., Lo, M., De Linage, C., Rodell, M., \& Swenson, S. C. (2013). Groundwater depletion in the Middle East from GRACE with implications for transboundary water management in the Tigris-EuphratesWestern Iran region. Water Resources Research, 49(2), 904-914. Retrieved from http://doi.org/10.1002/wrcr.20078 doi: 10.1002/wrcr.20078

Wahr, J., Swenson, S., \& Velicogna, I. (2006). Accuracy of GRACE mass estimates. Geophysical Research Letters, 33(6), L06401. Retrieved from http: // doi .org/ 10. 1029/2005GL025305 doi: 10.1029/2005GL025305 
Wan, Z. (2015). MOD11C3 MODIS/Terra Land Surface Temperature/Emissivity Monthly L3 Global 0.05Deg CMG V006. Retrieved from http://doi.org/ 10.5067/MODIS/MOD11C3.006 doi: 10.5067/MODIS/MOD11C3.006

Wang, De Linage, C., Famiglietti, J., \& Zender, C. S. (2011). Gravity Recovery and Climate Experiment (GRACE) detection of water storage changes in the Three Gorges Reservoir of China and comparison with in situ measurements. Water Resources Research, 47(12), n/a-n/a. Retrieved from http://doi .org/ 10.1029/2011WR010534 doi: 10.1029/2011WR010534

Wang, Qi, S., Niu, Z., \& Wang, J. (2004). Evaluating soil moisture status in China using the temperaturevegetation dryness index (TVDI). Canadian Journal of Remote Sensing, 30(5), 671-679. Retrieved from http://doi .org/10.5589/ m04-029 doi: 10.5589/m04-029

Wheaton, E., Wittrock, V., Kulshretha, S., Koshida, G., Grant, C., Chipanshi, A., \& Bonsal, B. (2005). Lessons learned from the Canadian drought years of 2001 and 2002: synthesis report (Tech. Rep.). Saskatchewan: Saskatchewan Research Council. Retrieved from http://www.agr.gc.ca/ eng/programs-and-services/list-of-programs-and-services/ drought-watch/managing-agroclimate-risk/lessons-learned-from -the-canadian-drought-years-2001-and-2002/ ? id=1463593613430

World Bank. (2006). Iraq: Country Water Resource Assistance Strategy: Addressing Major Threats to People's Livelihoods (Tech. Rep.). World Bank. Retrieved from http://siteresources.worldbank.org/INTWAT/Resources/Iraq.pdf

Yan, Moradkhani, H., \& Zarekarizi, M. (2017). A probabilistic drought forecasting framework: A combined dynamical and statistical approach. Journal of Hydrology, 548, 291-304. Retrieved from http://doi .org/10.1016/ j. jhydrol.2017.03.004 doi: 10.1016/j.jhydrol.2017.03.004 
Yan, Wu, B., Boken, V. K., Chang, S., \& Yang, L. (2016). A drought monitoring operational system for China using satellite data: design and evaluation. Geomatics, Natural Hazards and Risk, 7(1), 264-277. Retrieved from http: // doi.org/10.1080/19475705.2014.895964 doi: 10.1080/19475705.2014 .895964

Yang, Y., Long, D., Guan, H., Scanlon, B. R., Simmons, C. T., Jiang, L., \& Xu, X. (2014). GRACE satellite observed hydrological controls on interannual and seasonal variability in surface greenness over mainland Australia. Journal of Geophysical Research: Biogeosciences, 119(12), 2245-2260. Retrieved from http://doi.org/10.1002/2014JG002670 doi: 10.1002/2014JG002670

Yirdaw, S. Z., Snelgrove, K. R., \& Agboma, C. O. (2008). GRACE satellite observations of terrestrial moisture changes for drought characterization in the Canadian Prairie. Journal of Hydrology, 356(1-2), 84-92. Retrieved from http://doi.org/10.1016/j.jhydrol.2008.04.004 doi: 10.1016/ j.jhydrol.2008.04.004

Zhang, \& Bai, J. (2016). The spatial-temporal dynamic monitor of spring drought based on TVDI model in Guanzhong area. In 2016 fifth international conference on agro-geoinformatics (agro-geoinformatics) (pp. 1-6). IEEE. Retrieved from http://doi.org/10.1109/Agro-Geoinformatics.2016.7577685 doi: 10 .1109 /Agro-Geoinformatics.2016.7577685

Zhang, Hong, Y., Qin, Q., \& Liu, L. (2013a). VSDI: a visible and shortwave infrared drought index for monitoring soil and vegetation moisture based on optical remote sensing. International Journal of Remote Sensing, 34(13), 4585-4609. Retrieved from http://doi.org/10.1080/01431161.2013.779046 doi: 10 $.1080 / 01431161.2013 .779046$ 
Zhang, Hong, Y., Qin, Q., \& Zhu, L. (2013b). Evaluation of the visible and shortwave infrared drought index in China. International Journal of Disaster Risk Science, 4(2), 68-76. Retrieved from http://doi .org/10 . 1007/s13753-013-0008-8 doi: $10.1007 / \mathrm{s} 13753-013-0008-8$

Zhang, Zhang, Q., Werner, A. D., \& Liu, X. (2016). GRACE-Based Hydrological Drought Evaluation of the Yangtze River Basin, China. Journal of Hydrometeorology, 17(3), 811-828. Retrieved from http://doi .org/10.1175/ JHM-D-15-0084 . 1 doi: 10.1175/JHM-D-15-0084.1

Zhao, \& Dai, A. (2015). The Magnitude and Causes of Global Drought Changes in the Twenty-First Century under a LowModerate Emissions Scenario. Journal of Climate, 28(11), 4490-4512. Retrieved from http://doi.org/10.1175/ JCLI-D-14-00363. 1 doi: 10.1175/JCLI-D-14-00363.1 